\title{
Impacts of Conservative Endodontic Cavity on root canal instrumentation efficacy and resistance to fracture assessed in incisors, premolars and molars
}

by

Rajesh Krishan

A thesis submitted in conformity with the requirements

for the degree of Master of Science

Graduate Department of Dentistry

University of Toronto

C) Copyright by Rajesh Krishan 2013 


\title{
Impacts of Conservative Endodontic Cavity on root canal instrumentation efficacy and resistance to fracture assessed in incisors, premolars and molars
}

\author{
Rajesh Krishan \\ Master of Science, 2013 \\ Graduate Department of Dentistry \\ University of Toronto
}

\begin{abstract}
Conservative endodontic cavity (CEC) may improve fracture resistance of teeth but compromise instrumentation of canals. Extracted human intact maxillary incisors, mandibular premolars and molars were imaged with micro-CT and assigned to CEC or traditional endodontic cavity (TEC) groups ( $\mathrm{n}=10 /$ group/type). Canals were prepared and post-treatment micro-CT images obtained. These teeth along with the negative controls were then loaded to fracture. Mean proportion of untouched canal-wall was significantly higher only in distal canals of molars with CEC compared to TEC. Mean dentin volume removed was significantly smaller for CEC in all tooth types. Mean load-at-fracture for CEC was significantly higher in premolars and molars without differing significantly from the negative controls. While CEC was associated with compromised canal instrumentation only in the distal canals of molars, it conserved coronal dentin in all three tooth types and increased resistance to fracture in the mandibular molars and premolars.
\end{abstract}




\section{ACKNOWLEDGEMENTS}

First and foremost, I would like to thank my principal supervisor Dr. Shimon Friedman for his invaluable guidance, support and dedication throughout this research project and during the preparation of the manuscript. I am grateful for the privilege of being part of the Graduate Endodontic program at the University of Toronto and indebted for the knowledge and wisdom that he has been kind enough to share with me.

I would also like to thank my scientific advisory committee members, Dr. Anil Kishen and Dr. Thuan Dao, for their guidance, input and direction at various stages of the process. As well, I wish to thank Dr. Frank Paqué at the University of Zurich, Department of Endodontology, for his invaluable help and support with the micro-CT acquisition and analysis and Arezou Ossareh for her help with the fracture analysis. Importantly I also extend my appreciation to Dr. Carlos Boveda for providing the inspiration to research conservative endodontic cavities.

I wish to thank my fellow residents for enriching my experience with a special thank-you to my co-resident Dr. Anousheh Persadmehr, whose patience is the sole reason I am currently mildly competent with an array of computer programs, from refworks to powerpoint.

Finally and most importantly, I wish to acknowledge and thank my parents for the countless sacrifices they have made throughout the years to provide their children with opportunities they weren't fortunate enough to have. I am forever grateful for everything they have done for me and know that none of my accomplishments, however small, would have been possible without their love and support.

This study was supported in part by grants from the Canadian Academy of Endodontics Endowment Fund and Endo/Tech. 


\section{TABLE OF CONTENTS}

$\begin{array}{lll}\text { Abstract } & \text { ii }\end{array}$

Acknowledgements $\quad$ iii

List of appendices vi vi

I. GENERAL INTRODUCTION

1. Evolution of Dental Interventions - Minimally Invasive Dentistry 1

2. Apical Periodontitis 1

2.1 Etiology and Pathogenesis 1

2.2 Goals of Endodontic Treatment 2

3. The Endodontic Access Cavity 3

3.1 Role of the Endodontic Cavity 3

3.2 Traditional Endodontic Cavities 4

3.3 Conservative Endodontic Cavities 5

4. Instrumentation of the Root Canal 6

4.1 Objectives of Mechanical Instrumentation 6

4.2 Reciprocating Instruments $\quad 7$

5. Micro-Computed Tomagraphy 8

5.1 Main Features of Interest 8

5.2 Applications in Endodontic Research 8

5.3 Root Canal Instrumentation Efficacy 9

6. Fracture Resistance of Teeth after Root Canal Treatment 10

6.1 Factors Governing the Fracture Resistance of Teeth 10

6.2 Testing of Fracture Resistance 11

6.3 Incidence and Prevalence of Fractures after Root Canal Treatment 11

7. Treatment Outcomes of Root-Filled Teeth 12

7.1 Healing and Prevention of Apical Periodontitis 12

7.2 Survival 13

II. OBJECTIVES AND HYPOTHESIS

$\begin{array}{ll}\text { 1. Objectives } & 14\end{array}$

2. Hypothesis $\quad 15$

III. ARTICLE 16

IV. DISCUSSION 42 
V. CONCLUSION

VI. REFERENCES

53

VII. APPENDICES 


\section{LIST OF APPENDICES}

\section{Appendix 1. Figures}

Figure 1 Separate and merged pre-treatment (green) and post-treatment (red) microCT images of mandibular premolar (mesial view) where the root canal was accessed and instrumented through TEC with the green surface in the merged image representing untouched canal wall area.

Figure 2 Separate and merged pre-treatment (green) and post-treatment (red) microCT images of a mandibular premolar (mesial view) where the root canal was accessed and instrumented through CEC with the green surface in the merged image representing untouched canal wall area.

Figure 3 Load-at-fracture (mean and standard deviation) for extracted teeth with conservative (CEC), traditional (TEC) or no endodontic cavities (negative control), assessed in the Instron Universal machine. Similar letter case designation indicates non-significant differences; different letter case designations indicate a significant difference $(\mathrm{p}<0.05)$.

Figure 4 Typical fracture patterns in maxillary central incisors with CEC and TEC, loaded to fracture in the Instron Universal machine. Note the variable fracture patterns in teeth with both CEC and TEC.

Figure 5 Typical fracture patterns in mandibular molars with CEC and TEC, loaded to fracture in the Instron Universal machine. Note the mesio-distal fractures with varying apical extent observed in both CEC (left) and TEC (right). 
Figure 6 A typical outline of a conservative endodontic cavity (CEC) on the left along with the outline of a traditional endodontic cavity (TEC) on the right in mandibular molars. 


\section{THESIS}

\section{GENERAL INTRODUCTION}

\section{Evolution of Dental Interventions - Minimally Invasive Dentistry}

Operative dentistry is considered one of the pillars of dental practice and it traces its heritage to the principles of G.V. Black (1). One of its fundamental concepts, 'extension for prevention' $(1,2)$, had been followed universally for many decades. In recent years, operative dentistry has been subjected to a paradigm shift towards an unwavering, systematic respect for original tissue and considerable technical competence $(3,4)$. The philosophy of minimally invasive dentistry recognizes that caries is not cured by restorations and that cavities weaken the tooth (3). Interestingly, the shift to minimally invasive dentistry has been embraced even with the acknowledgement that there is yet limited structural evidence supporting it (3). Minimally invasive dentistry has been enabled by advances in adhesives and restorative materials along with the science of cariology, to drive an evolutionary change in restorative dentistry away from Black's 'extension for prevention' $(1,2,5)$. Indeed, the importance of this paradigm shift cannot be understated; it has been suggested that if only more dentists would embrace it, dentistry could improve the public's perception of its professionalism and honesty (6).

\section{Apical Periodontitis}

\subsection{Etiology and Pathogenesis}


Apical periodontitis, a sequel to endodontic infection, represents the host defense response to a microbial challenge from the root canal system (7). It is a destructive inflammatory process that may ensue as a consequence of caries, operative dentistry, periodontal disease, or trauma (7). The essential role of bacteria in the pathogenesis of apical periodontitis was initially demonstrated by Kakehashi in his seminal work on germ-free rats (8) and it has been corroborated in subsequent studies (9-11).

The canal system within the roots of teeth provides a selective environment for the establishment and proliferation of microorganisms and their subsequent egress into the periradicular tissue (7). The host's defense system responds to this insult by way of a complex array of immunological mechanisms, some of which protect the pulp and the periapical region and others which mediate tissue and bone destruction (12). However, the response mounted by the host is largely unable to reach the invading microorganisms, which frequently persevere within the closed root canal environment (7). Therefore, apical periodontitis is not self-resolving and its progression and severity depend upon the nature, virulence and identity of the microbial invasion and the specific response of host's defense system (12).

\subsection{Goals of Endodontic Treatment}

The essential goal of endodontic treatment is the prevention or elimination of apical periodontitis by means of eradication or containment of the causative microorgainisms (13). The goal may be achieved by disinfection of the canal system, using various chemomechanical methods, and by prevention of reinfection using a root canal filling. Due to the limitations inherent to the mechanical and chemical disinfection process (14, 
15) it is paramount that these techniques be employed in combination. Such combination more effectively reduces the bacterial load within the root canal system even if complete elimination of the microbial persistence is unattainable (16-19).

Microbial colonization of the root canal system following endodontic treatment is the main cause of persistent post-treatment apical periodontitis (20). The root canal filling is thus expected to prevent the proliferation of any residual bacteria by limiting nutrients and available space, as well as preventing bacterial ingress (21). The combination of the aforementioned therapeutic steps in conjunction with appropriate diagnosis and treatment planning form the essential elements required to achieve the goals of endodontic treatment (22).

\section{The Endodontic Access Cavity}

\subsection{Role of the Endodontic Cavity}

Adequate access is essential for effective delivery of therapeutic chemomechanical measures into the root canals. In this regard, the access cavity may be considered the single most important phase in root canal treatment, as all of the steps that follow may be compromised if adequate access is lacking (23). An inadequate endodontic cavity preparation may make the location, negotiation, debridement, disinfection and filling of the root canal system difficult; any one of these factors in isolation, or their combination may lead to persistence of infection after treatment $(24,25)$. Indeed, an adequate endodontic cavity is vital to quality treatment, prevention of iatrogenic complications and 
to ultimate healing of apical periodontitis $(24,25)$. Thus, the specific objectives of endodontic cavities are to facilitate complete debridement, irrigation, shaping, cleaning and filling of the root canal system $(23,25)$. These specific objectives are in-line with the overall goals of endodontic therapy, as it is only in the presence of the former that the elimination or prevention of apical periodontitis can be attained.

\subsection{Traditional Endodontic Cavities}

The principles of traditional endodontic cavities were established many decades ago and have remained unchanged over time. They were described by Ingle (24) with direct reference to the fundamentals of restorative dentistry defined by Black (1). In the endodontic context, the principles of the cavity include 'outline', 'convenience', 'retention' and 'resistance' form with 'toilet of the cavity' and 'elimination of residual caries' being additional principles (24). Each of these principles relates to different areas of the tooth as the endodontic cavity is considered a continuum from the enamel surface to apex (25). The 'outline' form dictates the exterior occlusal extent of the cavity while 'convenience' form relates to dentin removal in specific areas to achieve straight-line access to the root canal orifices (24). Underlying these principles is Black's concept of 'extension for prevention', which promotes the sacrifice of additional tooth structure to prevent iatrogenic complications and to best achieve the ultimate goals $(1,2,24)$. 'Extension for prevention' in endodontic cavities involves removal of dentin obstructions to extend the straight-line access to the apical foramen or to the initial curvature of the canal (23-25). While on the one hand, applying the concept of 'extension for prevention' facilitates treatment procedures and avoids procedural complications, it removes valuable dentin, leaving tooth structure biomechanically compromised and less able to withstand 
functional loads after endodontic treatment.

\subsection{Conservative Endodontic Cavities}

As the endodontic cavity is inexorably linked to cavity design in restorative dentistry, it is only natural that the changes occurring in latter would impact on the former. Similar to the evolution in restorative dentistry, a shift has been proposed to transform the endodontic cavity from the traditional 'operator centric' design to one that focuses on dentin preservation and the endodontic-restorative interface (26-28). Moreover, the evolved endodontic cavity should be considered key to restorative stability and long-term retention of the tooth after treatment $(26,27)$. The preservation of coronal and radicular

dentin during endodontic treatment procedures greatly impacts upon the restorative treatment that follows and it plays a crucial role in the survival of the tooth (28-31). Because no restorative material or technique can overcome lost dentin biomaterial, especially in key areas of the tooth, treatment steps directed towards dentin conservation are essential as the primary means to buttress the root-filled tooth (26).

The emerging concept of conservative endodontic access prioritizes the removal of restorative materials before tooth structure, of enamel before dentin and of occlusal tooth structure before cervical dentin. It disregards the traditional requirements of a straightline access and complete unroofing of the pulp chamber and it emphasizes the importance of preservation of the crucial pericervical dentin (located $4 \mathrm{~mm}$ above and below the crestal bone) to the greatest extent possible $(26,27)$. 


\section{Instrumentation of the Root Canal}

\subsection{Objectives of Mechanical Instrumentation}

Mechanical instrumentation carried out within the root canal system is a key component of endodontic therapy $(14,16-18)$. The main objectives of root canal instrumentation are to remove pulp from the main root canal(s) and to create sufficient space for irrigation, medication and root filling. While these objectives are pursued, it is essential to preserve the integrity of the apical canal anatomy, avoid iatrogenic damage to the root structure and supporting tissues, facilitate canal filling, and preserve sound root dentin to maintain the long-term function of the tooth (14).

Schilder (22) suggested that root canal instrumentation must respect the individual and unique anatomy of each root canal and aim to achieve five design objectives: 1) a continuously tapering funnel from the apex to the access cavity, 2) a cross-sectional diameter that is narrower at every point apically, 3) a preparation that flows with the shape of the original canal, 4) the apical foramen that remains in its original position and 5) the apical opening that is kept as small as practical (22). Four biologic objectives were also emphasized: 1) confinement of instrumentation to the roots, 2) no forcing of necrotic debris beyond the apical foramen, 3) removal of all tissue from the root canal space, and 4) creation of sufficient space for intracanal medications (22). There have been a variety of instruments and techniques advocated throughout the years that proposed to best accomplish the above objectives of instrumentation $(14,32)$ with an evolution of traditional concepts noted in the past decade. 


\subsection{Reciprocating Instruments}

Traditional root canal instruments have been made of steel and manipulated with the operator's fingers $(14,33)$. In the past two decades, the use of nickel-titanium (Ni-Ti) instruments has become increasingly popular due to their flexibility, efficiency and ability to maintain the canal anatomy (34-37). Shortly after the introduction of Ni-Ti instruments for manual use, engine-driven rotating instruments were introduced that critically facilitated the instrumentation process (32). The pioneering rotary instrument systems were comprised of several instruments used in sequence. Over the years, the numbers of instruments within systems have been gradually reduced as designs have become more sophisticated (35-37). This process culminated in the current availability of 'systems' that employ a single instrument to carry out the required root canal instrumentation (38-40). The proposed main benefits of the single instrument 'system' are cost-effectiveness, elimination of possible prion cross-contamination and a reduced instrument fatigue associated with single use (41-43). In parallel to the gradual reduction in instrument numbers, a mode of reciprocating rotation of instruments was introduced (41) with the specific intent to be employed with the single-instrument 'systems' (41-46).

The reciprocating motion was initially advocated as an extension of Roane's balanced force technique (47) to rotary instrumentation. It offered other advantages in comparison to continuous rotation of instruments: reduced instrument fatigue (42-44) and better compliance with canal anatomy with lower risk of procedural errors $(40,45)$. All those features notwithstanding, when a single instrument was used in reciprocation, the resulting bacterial load reduction did not significantly differ from that achieved with continuous rotation and hand instruments (46). 
As the designs of root canal instruments continued evolving, a greater awareness of the need to preserve dentinal structure within the canal system emerged. To this end, regressing tapers farther away from the tip of the instrument limit dentin reduction in the coronal aspect of the canal (38). One such single instrument 'system' that incorporates reciprocating rotation and regressing tapers is WaveOne (Dentsply Maillefer, Ballaigues, Switzerland) with tapers of $8 \%$ in the last $3 \mathrm{~mm}$ but a taper of $5.5 \%$ further from the tip; this design improves flexibility while conserving dentin in the coronal two-thirds of the root canal (38).

\section{Micro-Computed Tomography}

\subsection{Main Features of Interest}

The micro-computed tomography (micro-CT) system employs microfocal spot x-ray sources and high-resolution detectors, allowing for projections rotated through multiple viewing directions to produce three-dimensional (3D) reconstructed images of samples (48). These reconstructed 3D images represent spatial distribution maps of linear attenuation coefficients determined by the energy of the x-ray source and the atomic composition of the material sampled (48).

\subsection{Applications in Endodontic Research}

When used in conjuction with mathematical modeling and reconstruction, micro-CT is capable of detailed 3D analysis of the root canal system $(49,50)$. Micro-CT acquisition is non-destructive and it allows rapid evaluation of the tooth in a detailed manner from 
series of cross-sectional slices generated through a tooth, which are then reconstructed to visualize and evaluate various parameters; these parameters make micro-CT an ideal tool to assess the effects of root canal instrumentation (50).

Initial uses of micro-CTs innovative imaging technique involved evaluation of anatomy, tooth morphology, surface and volume changes (51-53). Although resolution and projection errors were early concerns, advances in mathematical modeling and computer software quickly resolved them. By the year 2000, appropriate accuracy validation was completed for parameters such as volume and surface area as well as additional descriptors of canal shape such as Structure Model Index (SMI) and thickness $(53,54)$.

In the subsequent years micro-CT has been well validated and employed in the study of canal curvatures (49), percentage of instrumented canal wall (55-60) and volume changes within the tooth (61). Currently, micro-CT techniques produce serial images of dental tissues and root canal morphology of higher resolution than any other computed tomography available. Although micro-CT is not available for use in a clinical dental setting it can be considered as the reference standard in 3D dental research $(53,62)$.

\subsection{Root Canal Instrumentation Efficacy}

Evaluation of instrumented root canal cleanliness has been traditionally conducted with serial sectioning (horizontal or longitudinal) in conjunction with SEM imaging or histology. This method is fraught with artifacts, including contamination and loss of debris during the sectioning process $(33,51,52,54,63-65)$. Because the imaging of teeth with micro-CT allows three-dimensional replication of the root canal system with different experimental steps (pre-, intra- and post-operative), it supports computer-aided 
measurements of quantitative differences between those images. Among the parameters that can be quantified, micro-CT imaging enables the determination of the canal wall surfaces touched and untouched by instruments and of canal transportation in three dimensions (14). These parameters are currently used as measures of the efficacy of root canal instrumentation $(54,65)$.

\section{Fracture Resistance of Teeth after Root Canal Treatment}

\subsection{Factors Governing the Fracture Resistance of Teeth}

Fracture resistance has been studied extensively due to its paramount importance with regards to the function and survival of the tooth. Evaluation of restorative cavity preparations reveals that all occlusal cavity preparations decrease the fracture resistance of teeth in proportion to the width of the preparation (66). This concept was subsequently extended to endodontics, as it was suggested that cuspal deflection increased with increasing cavity size and was greatest in the presence of an endodontic cavity (67).

The mere preparation of an endodontic cavity results in a deep and extended cavity, critically reducing the amount of residual dentin, which may compromise the fracture resistance of the tooth even when it is restored $(31,68)$. The fracture predilection of endodontically treated teeth is governed by biomaterial and biomechanical considerations as well as specific risk factors: 1) chemical (effects of endodontic irrigants and medicaments on dentin), 2) microbial (effects of bacteria-dentin interaction), 3) dentin (effects of tooth structural loss), 4) restorative (effects of post and core restorations) and 
5) age (effects of age changes in dentin) (69). The tooth type is also important, as intact pulpless anterior teeth that have not lost further tooth structure beyond the endodontic cavity are at minimal risk for fracture, while posterior teeth that are subject to larger occlusal loads during function are at greater risk (69).

\subsection{Testing of Fracture Resistance}

Fracture testing of teeth has been traditionally performed with the aid of the Instron Universal Testing machine (Instron, Canton, MA). This device has the capacity to record a variety of parameters related to the loading of different structures. The Instron Universal Testing machine is used to determine mechanical properties of materials and components using tension, compression, flexural, fatigue and torsional forces (70).

The use of the Instron Universal Testing machine has been well-validated in dentistry for a variety of procedural testing including load-at-fracture under a constantly increasing compressive force, to provide an estimate of fracture resistance $(66,71-73)$. The use of a metal sphere to load the teeth has been suggested to be ideal as it contacts the functional and non-functional cusps in positions close to their loading clinically $(73,74)$. A complicating variable is the fact that the presence of various permanent restorative materials such as posts, resins, amalgam, porcelain and metals may affect the fracture resistance under test conditions (71-73) and may obscure the direct effect of dentin loss on specific fracture resistance of the tooth being tested.

\subsection{Incidence and Prevalence of Fractures after Root Canal Treatment}


The epidemiology of tooth fractures has been assessed in a variety of time frames and sample populations using different nomenclature. One study (75) conducted over a period of 3 to 4 months, reported that of 543 tooth fractures, about $86 \%$ were complete cusp fractures, $13 \%$ were incomplete or suspected cusp fractures and $1 \%$ were root fractures. The study suggested that during any given year, $6 \%$ of adult patients with at least one posterior tooth at risk would experience a complete cusp fracture in the absence of caries, with an incidence rate of 20.5 (76) to 72.7 per 1000 person-years (75). It was further noted that cusp fractures were more likely to extend subgingivally in root-filled teeth than in untreated teeth (76). The prevalence of complete cusp fractures was reported at about $2 \%$ for both amalgam and composite restorations (77). It was also suggested that the impact of endodontic cavities and canal instrumentation on fracture resistance varies for different tooth types; force required to fracture endodontically instrumented premolars was $30 \%$ lower than that required to fracture non-instrumented premolars, while the force required for the instrumented canines was comparable to that of non-instrumented canines (78). Moreover, excessive removal of dentin and the presence of noncircular canals and thin canal walls increase the risk for root fracture, particularly with certain tooth types (79).

\section{Treatment Outcomes of Root-Filled Teeth}

\subsection{Healing and Prevention of Apical Periodontitis}

As the primary goal of endodontic treatment is the healing or prevention of apical periodontitis (13), healing is routinely evaluated as the main outcome after root canal 
treatment. Evaluation of outcome has been primarily based on radiographic and clinical measures $(80,81)$. Both measures have inherent limitations; interpretation of periapical radiographs is potentially influenced by the evaluator's bias (82-85), while reporting of

clinical symptoms may be influenced by the patient's subjective input. Accounting for the methodology of studies, the current best evidence suggests that the potential of teeth that are free of apical periodontitis to remain so after root canal treatment is 93 to $98 \%$ (86), while the potential of teeth with apical periodontitis to completely heal following root canal treatment is 73 to $86 \%(86)$.

\section{$\underline{7.2 \text { Survival }}$}

Tooth survival has been assessed over the years as a secondary outcome, even though it may be more pertinent from a patient's perspective than healing per se. While many factors have been studied for their association with tooth survival (87-89), the available evidence suggests that tooth survival is often influenced by the distribution, amount, strength and integrity of remaining tooth structure, the occlusal and functional loading on the tooth and the manner in which that load is distributed within the remaining tooth structure (90). Indeed, it has been suggested that the most important factor regarding the survival of root-filled teeth is the amount of remaining dentin (90-93).

A recent systematic review indicated that the survival rate for root-filled teeth 2 to 10 years after treatment ranged from 86 to $93 \%$ (87). When the survival rate of root-filled teeth is compared to untreated teeth, it is evident that the former is substantially lower, especially in molars (94). 
When the reasons for extraction of root-filled teeth have been studied, fractures emerged as the main cause, accounting for up to $47 \%$ of the extractions, while persistent apical periodontitis accounted for only about 9 to $12 \%$ of extractions (94-98). The significance of conserving dentin has been highlighted as a critical factor responsible for the fate of root-filled teeth (97). This reality reinforces the importance of dentin conservation when preparing the endodontic cavity.

\section{OBJECTIVES AND HYPOTHESES}

\section{Objectives}

The objectives of this in vitro study were to assess the potential impacts of conservative endodontic cavities on 1) efficacy of root canal instrumentation and 2) resistance to fracture of extracted maxillary incisors, mandibular premolars and mandibular molars.

The specific aims of the study were to compare teeth with conservative endodontic cavities to those with traditional endodontic cavities using the following outcome variables:

- Proportion of canal wall surface untouched by instruments measured by micro-CT

- Volume of dentin removed measured by micro-CT

- Load-at-fracture under continuous force applied in the Instron Universal Testing machine 


\section{Hypotheses}

It was hypothesized that in teeth with a conservative endodontic cavity, compared to teeth with a traditional endodontic cavity:

1) The proportion of untouched canal wall area would be significantly higher

2) The volume of dentin removed would be significantly less

3) The load-at-fracture would be significantly higher

In both the conservative and traditional cavity groups:

4) The load-at-fracture would be significantly lower than in intact teeth without an endodontic cavity. 


\section{ARTICLE}

Submitted for Publication

\section{Impacts of Conservative Endodontic Cavity on root canal instrumentation efficacy and resistance to fracture assessed in incisors, premolars and molars}

Rajesh Krishan DDS*, Frank Paqué DMD***, Arezou Ossareh BASc*, Anil Kishen MDS, PhD*, Thuan Dao DMD, MSc, PhD**, and Shimon Friedman, DMD*

University of Toronto, Disciplines of Endodontics* and Prosthodontics**

University of Zurich, Department of Endodontology***

Corresponding Author:

Dr. Shimon Friedman

Faculty of Dentistry, University of Toronto

124 Edward Street, Toronto, Ontario M5G 1G6

Canada

s.friedman@utoronto.ca

Running title: Impacts of conservative endodontic cavities

\section{Acknowledgments}

This study was supported in part by grants from the Canadian Academy of Endodontics Endowment Fund and Endo/Tech. The authors thank Dr. Carlos Boveda for the inspiration to research conservative endodontic cavities. The authors deny any conflict of interest related to this study. 


\begin{abstract}
Introduction: Conservative endodontic cavity (CEC) may improve fracture resistance of teeth but compromise instrumentation of canals. This study assessed the impacts of CEC on both variables in three tooth types. Methods: Extracted human intact maxillary incisors, mandibular premolars and molars (n=20/type) were imaged with micro-CT ( $20 \mu \mathrm{m}$ resolution) and assigned to CEC or traditional endodontic cavity (TEC) groups ( $n=10 /$ group/type). Minimal CEC's were plotted on scanned images. Canals were prepared with WaveOne instruments using $1.25 \% \mathrm{NaOCl}$ and post-treatment micro-CT images obtained. Proportion of untouched canal-wall and dentin volume removed (DVR) for each tooth type was analyzed with independent-samples t-test. The 60 instrumented and 30 intact teeth (negative control; $n=10 /$ type) were loaded to fracture in the Instron Universal Testing machine $(1 \mathrm{~mm} / \mathrm{min})$ and data analyzed with one-way ANOVA and Tukey test. Results: Mean proportion of untouched canal-wall was significantly higher $(p<0.04)$ only in distal canals of molars with CEC $(57.2 \pm 21.7 \%)$ compared to TEC $(36.7 \pm 17.2 \%)$. Mean DVR was significantly smaller $(p<0.003)$ for CEC than for TEC in incisors $\left(16.09 \pm 4.66\right.$ vs. $\left.23.24 \pm 3.38 \mathrm{~mm}^{3}\right)$, premolars $\left(8.24 \pm 1.64\right.$ vs. $\left.14.59 \pm 4.85 \mathrm{~mm}^{3}\right)$ and molars $\left(33.37 \pm 67.71 \mathrm{~mm}^{3}\right)$. Mean load-at-fracture for CEC was significantly higher $(\mathrm{p}<0.05)$ than for TEC in premolars $(586.8 \pm 116.9$ vs. $328.4 \pm 56.7 \mathrm{~N})$ and molars $(1586.9 \pm 196.8$ vs. $641.7 \pm 62.0 \mathrm{~N})$ without differing significantly from the negative controls. Conclusions: While CEC was associated with the risk of compromised canal instrumentation only in the distal canals of molars, it conserved coronal dentin in the three tooth types and conveyed a benefit of increased resistance to fracture in the mandibular molars and premolars.
\end{abstract}


Keywords: Endodontic cavity; fracture resistance; dentin volume removed; instrumentation efficacy

\section{Introduction}

The design of the traditional endodontic cavity (TEC) for different tooth types has been established several decades ago and has remained unchanged with only minor modifications. The principles of TEC were defined by Ingle (1) using terminology borrowed from restorative dentistry: 'Outline form' relates to projection of the pulp chamber over the occlusal surface of the tooth crown. 'Convenience form' relates to removal of the dentin interfering with direct access to canal orifices and curvature. While 'retention form' and 'resistance form' relate to the shape of the apical few millimeters of

the root canal, 'extension for prevention' suggests removal of additional tooth structure in order to prevent procedural complications and to optimize canal debridement. Thus, TEC is primarily designed to facilitate cleaning, shaping and filling of the root canals while avoiding excessive removal of tooth structure $(1,2)$.

The removal of enamel and dentin to accommodate TEC - coronal to the pulp chamber, along the chamber walls and around canal orifices - may weaken the resistance of the residual tooth structure to fracture under functional loads (3-5). Indeed, coronal and radicular fracture of root-filled teeth, frequently leading to extraction (6-9), has become a major concern undermining the confidence of dentists and patients in the long-term benefits of endodontic treatment $(5,10)$. 
In recent years, Clark and Khademi $(10,11)$ have described a modified endodontic cavity concept designed to minimize tooth structure removal and to improve fracture resistance of root-filled teeth. The novel conservative endodontic cavity (CEC) involves preservation of the pulp chamber roof and pericervical dentin (10). It represents a paradigm shift away from coronally divergent walls, complete unroofing with exposure of all pulp horns and straight-line access into the canals and farther to the curvature (10). Clinically, the specific outline of CEC for each tooth can be plotted on cone-beam computed tomography (CBCT) images (12). In this manner all canals are identified in advance and the trajectory to access each canal is projected to outline the smallest cavity possible.

With a typically confined outline and no convenience form, CEC increases the degree of difficulty associated with cleaning, shaping and filling of the root canals $(10,11)$. The confined access may present risks of inefficient canal instrumentation and occurrence of procedural errors (2). On the other hand, the tooth structure preserved may offer a benefit of improved fracture resistance of the treated tooth under functional loads (5). Specific investigation into CEC is warranted to assess the associated risks and benefits for different tooth types.

Mechanical efficacy of canal instrumentation is currently assessed routinely with nondestructive micro-CT imaging (13-18). Analysis of images before and after cleaning and shaping allows accurate measurements of changes in root canal morphology, volume of dentin removed, remaining dentin thickness, transportation of canal pathways and, importantly, the canal wall surface area contacted and untouched by the instruments (13$18)$. 
The resistance of teeth to fracture is currently assessed routinely by subjecting them to simulated functional loading in the Instron Universal Testing machine, until fracture occurs $(19,20)$. Loading parameters can be controlled, including the force, point and direction of contact, and the load-at-fracture and time-to-fracture recorded $(19,20)$.

To assess the potential risks and benefits associated with CEC, the objectives of this in vitro study were to determine the efficacy of root canal instrumentation and the resistance to fracture in different tooth types. The specific aims were to characterize canal instrumentation performed through CEC and TEC, with regards to (A) proportion of untouched canal wall surface measured by micro-CT, (B) volume of dentin removed measured by micro-CT, and (C) load-at-fracture under dynamic loading conditions in the Instron Universal Testing machine. We hypothesized that in the CEC group: (1) the proportion of untouched canal wall area would be significantly higher, (2) the volume of dentin removed significantly less and (3) the load-at-fracture significantly higher than in the TEC group. We also hypothesized that (4) the load-at-fracture would be significantly lower in both CEC and TEC groups than in the negative control.

\section{Materials and Methods}

Ethics approval was attained and 90 previously extracted human non-carious, mature, intact, maxillary central incisors, mandibular second premolars and mandibular first molars were selected to represent the three main tooth types $(\mathrm{N}=30$ teeth/type). Teeth were stored in a $0.1 \%$ thymol solution at $4{ }^{\circ} \mathrm{C}$ until used. They were exposed by phosphor

plate radiography (Digora Soredex, Helsinki, Finland) from two perpendicular views and 
characterized for overall dimensions, length and degree of canal curvature. These characteristics were used to match teeth within each type when allocated into groups.

\section{Sample size and groups}

In the absence of fracture resistance data directly applicable to this study design, selected studies on root canal instrumentation efficacy were used as reference (14-18); these studies typically assessed 6 to 30 canals/group and reported differences in the proportion of untouched canal wall area in the range of $4 \%$ to $100 \%$. To detect differences in proportion of untouched canal wall area of at least $12 \%$ in incisors/premolars and $23 \%$ in molars, the sample size was set at 10 teeth/type (10 and 30 canals/group for incisors/premolars and molars, respectively) for assessment with $80 \%$ power and $5 \%$ significance.

The 30 teeth/type were divided to three groups as follows: 20 teeth/type were equally allocated to groups CEC (experimental) and TEC (control) and 10 teeth/type were allocated to a negative control group for fracture testing only.

\section{Micro-CT assessment of instrumentation efficacy and volume of dentin removed}

Teeth in the CEC group were mounted in a custom-made device (17) and imaged with micro-CT ( $\mu$ CT 40; Scanco Medical, Brüttisellen, Switzerland) at an isotropic resolution of $20 \mu \mathrm{m}$ (pre-treatment scan). These scans were used to plot the CEC outline for each tooth by projecting the access trajectory to each canal orifice that will require the least tooth structure removal. Subsequently, CEC was drilled with a mosquito diamond bur (F392-016, Axis Dental, Coppell, TX) at high speed. In the incisors, drilling was initiated 
$1 \mathrm{~mm}$ palatal to the incisal edge and extended apically along the long axis. In the premolars, drilling was initiated $1 \mathrm{~mm}$ buccal to the central fossa and extended apically maintaining a part of the chamber roof and lingual shelf. In the molars, drilling was initiated at the mesial one quarter of the central fossa and extended apically and distally while maintaining part of the chamber roof (Fig. 1). Canals were located while minimizing mesial-distal, buccal-lingual and circumferential pericervical dentin removal. Teeth in the TEC group were pre-scanned as described above but had an endodontic cavity prepared as per conventional guidelines $(1,2)$ (Fig. 1). The enamel in all teeth was beveled with a tapered diamond bur.

All canals were negotiated with size $10 \mathrm{~K}$-type files (Flexofile; Dentsply Maillefer, Balleigues, Switzerland) to the major apical foramen as observed under the microscope at 4X magnification. Working length was measured in the pre-treatment scan from the appropriate reference point to $0.5 \mathrm{~mm}$ short of the portal of exit and confirmed radiographically. A glide path was established with a size 15 K-type file and canals instrumented to length with WaveOne reciprocating instruments (Dentsply Maillefer) Primary (tip size 25) in the premolars and mesial canals of molars, and Large (tip size 40) in the incisors and distal canals of molars - as per the manufacturer's protocol. Each canal was intermittently irrigated with $5 \mathrm{ml}$ of $1.25 \% \mathrm{NaOCl}$ using a ProRinse sidevented 30 G needle (Dentsply Tulsa Dental Specialties, Tulsa, OK) at standardized intervals. After cleaning and shaping, the teeth were imaged again with micro-CT at 20 $\mu \mathrm{m}$ to capture the instrumented canal shape (post-treatment scan).

The pre- and post-treatment scans were precisely repositioned through a softwarecontrolled iterative superimposition algorithm (17). The proportion of instrumented and 
untouched canal wall surface areas and the volume of dentin removed were determined with custom-made software (IPL; Scanco Medical, Brüttisellen, Switzerland). Based on voxel size, root canal surface was termed "untouched" when less than 20 microns of dentin were removed.

\section{Mechanical testing of load-at-fracture}

Thirty teeth $(n=10 /$ type $)$ remained intact without endodontic cavities drilled and served as the negative control group for mechanical testing. These teeth and the 60 accessed and instrumented teeth in the CEC and TEC groups were mounted on brass rings with the roots embedded in self-curing resin (SR Ivolen, Ivoclar Vivadent, Schaan, Lichtenstein) up to $2 \mathrm{~mm}$ apical to the cemento-enamel junction. In all incisors, a groove was drilled with a \#4 round bur into the enamel coronal to the cingulum.

All 90 tooth specimens were placed in a custom made water bath and mounted in the Instron Universal Testing Machine (Instron, Canton, MA). Premolars and molars were loaded at the central fossa at $30^{\circ}$ to the long axis of the tooth, while incisors were loaded at the drilled palatal groove at $135^{\circ}$. Continuous compressive force at a cross-head speed of $1 \mathrm{~mm} / \mathrm{min}$ was applied until failure occurred, defined as a $25 \%$ drop in the applied force. The load-at-fracture was recorded in Newtons $(\mathrm{N})$.

\section{Analysis}

The mean percentage of untouched canal wall surface area was calculated for groups CEC and TEC, for the total canal length and for the coronal, middle and apical canal

levels. Similarly, the mean dentin volume removed was calculated for groups CEC and 
TEC for the entire tooth and for the crown and three canal levels. Data sets were calculated independently for the incisors, premolars and the molars' mesial and distal canals. Data for the CEC and TEC groups were then compared with an independent samples $t$-test.

The mean load-to-fracture values were calculated for each tooth type in groups CEC, TEC and the negative control. One-way ANOVA and a post-hoc Tukey test were used to compare data among and between groups. All tests were two-tailed and interpreted at the $5 \%$ significance level.

\section{Results}

\section{Instrumentation efficacy}

No fractures of WaveOne instruments occurred throughout the experiment. Typical examples of superimposed pre- and post-treatment micro-CT images are shown in Fig. 2 (maxillary central incisors in the CEC and TEC groups) and Fig. 3 (mandibular molar in the CEC group). The mean proportion of total untouched wall area (Table 1) was highest in the mandibular premolars and lowest in the mesial roots of the mandibular molars. It ranged from $36.7 \pm 17.2 \%$ (distal canals of molars with TEC) to $76.1 \pm 17.3 \%$ (premolars with TEC) and was statistically significantly higher $(\mathrm{p}<0.04)$ in the distal canals of molars with CEC than in those with TEC. While only small differences between the two groups were observed in the mesial canals of molars and the premolars, the difference between the CEC and TEC groups in the incisors was more substantial but not statistically significant. Assessed at three canal levels, the proportion of untouched wall 
area differed significantly between the groups only in the apical third of molar distal canals; it was higher $(\mathrm{p}<0.05)$ for CEC than for TEC.

\section{Volume of dentin removed}

The mean volume of dentin removed (Table 2) was least in the mandibular premolars and greatest in the mandibular molars. It ranged from $8.24 \pm 1.64 \mathrm{~mm}^{3}$ (premolars with CEC) to $67.71 \pm 14.12 \mathrm{~mm}^{3}$ (molars with TEC) and was statistically significantly smaller ( $\mathrm{p}<$ 0.003) in the CEC group than in the TEC group in all tooth types. Overall, in incisors, premolars and molars with TEC the dentin volume removed was $44 \%, 77 \%$ and $103 \%$ larger, respectively, than in matched teeth with CEC. Assessed at the crown and three canal levels, the dentin volume removed differed significantly only at the crown level; it was less $(\mathrm{p}<0.002)$ in the CEC group than in the TEC group for all tooth types.

\section{Load-at-fracture}

The mean load-at-fracture (Table 3) was lowest in the mandibular premolars across all three groups. In the CEC and TEC groups, it ranged from $328.4 \pm 56.7 \mathrm{~N}$ (premolars with TEC) to $1586.9 \pm 196.8 \mathrm{~N}$ (mandibular molars with CEC). For the premolars and molars, the mean load-at-fracture values in the CEC group were significantly higher $(\mathrm{p}<0.05)$ than in the TEC group and they did not differ significantly from the intact teeth (negative control). Conversely, in the TEC group the load-at-fracture in premolars and molars was significantly lower $(\mathrm{p}<0.05)$ than in the negative control. For the incisors, the mean load-at-fracture did not differ significantly among the three groups.

Qualitative assessment of the fractures in the incisors revealed variable patterns. Among the premolars, mostly cuspal chipping was observed in the CEC group while wall 
fractures were consistently observed in the TEC group extending below the cementoenamel junction (Fig. 4). In the molars, mesio-distal fractures with varying apical extent were observed in both CEC and TEC groups.

\section{Discussion}

The concept of CEC $(10,11)$, introduced a few years ago in the context of minimally invasive dentistry (21), has received limited attention among clinicians without impacting on the mainstream practice of endodontics. The suggested attributes - benefit of tooth structure conservation and increased difficulty of treatment $(10,11)$ - have not been well supported by research data. This study was designed to quantitatively assess the main potential benefits and risks associated with CEC so as to provide a much needed research base to support further discussion of this controversial issue.

Intact maxillary central incisors, mandibular second premolars and mandibular first molars were selected and distributed among matched groups to reduce variables to minimum. As the relative anatomy of tooth crowns and pulp chambers within each of the anterior, premolar and molar tooth types is rather uniform, the results of this study could be generalized beyond the specific teeth tested. The configuration of CEC's was designed using the principles of Clark and Khademi (10) as a loose framework. Appropriate modifications were made for the incisors, premolars and molars. The minimal cavity outline for each tooth was plotted with the aid of pre-treatment micro-CT imaging that is not clinically applicable; however, clinicians may use small field-of-view cone-beam CT imaging as reference for planning the outline of CEC in clinical practice (12). 
The experimental methods conformed to previously established protocols. Teeth were imaged with micro-CT with adequate resolution before and after access cavity and root canal preparation, to accurately register the dentin removed at the levels of the tooth crown and along the canals and to map canal wall areas that remained untouched by instruments (14-18). To mitigate the risk of instrument fracture when cleaning and shaping canals through a restrictive access such as CEC, the WaveOne reciprocating instruments were selected for their higher fatigue resistance compared to instruments used in continuous rotation $(22,23)$. Also, with a smaller coronal taper than many other instrument systems, use of the WaveOne instruments was expected to conserve radicular dentin. Fracture resistance was assessed with the ubiquitous Instron Universal Testing machine $(19,20)$. The accesses cavities were not restored prior to loading to avoid potential confounding by variables related to restorations.

A compromised canal instrumentation efficacy was observed in the distal canals of the mandibular molars with CEC, suggested by the larger proportion of untouched canal walls, specifically in the apical third. Thus, our first hypothesis was rejected for the premolars and incisors. Compared to incisors and premolars, the distal canals of mandibular molars typically have longer oval canals, larger canal tapers in the buccallingual direction and a wide range of apical diameters (24). In these canals, instruments frequently fail to touch a large proportion of the canal walls especially in the apical third regardless of the technique used, resulting in over $60 \%$ of canal walls remaining untouched (18). Our findings corroborated the previous reports $(18,24)$ and indicated that the challenge of instrumentation in oval-shaped canals, such as in distal roots of mandibular molars, might be amplified by the restrictive CEC. To gain better access to 
the canal walls, the distal outline of CEC may have to be slightly extended buccolingually to more closely match the wide dimension of the distal canal. This may also allow approaching the distal canal as two separate pathways, suggested to improve the efficacy of instrumentation (18). As for the risk of instrument fracture, such did not occur in any of the teeth with CEC when canals were cleaned and shaped with WaveOne instruments.

As expected, CEC was consistently associated with less dentin removal than TEC, primarily at the tooth crown level coronal to the canal orifices. While our second hypothesis was accepted for the three tooth types, the relative conservation of coronal dentin was greatest in the molars, moderate in the premolars and least in the incisors. At the same time, the fracture resistance of molars and premolars with CEC was about 2.5fold and 1.8-fold more, respectively, than in matched teeth with TEC, while the incisors showed comparable resistance to fracture for both cavity designs. Thus, our third hypothesis was accepted for the premolars and molars only. Importantly, the fracture resistance of the molars and premolars with CEC was comparable to that of the intact teeth of the same type. In contrast, the teeth with TEC were less resistant than the intact teeth. Thus, our fourth hypothesis was only accepted for the teeth with TEC. Taken together, our data corroborated the previous reports that the preservation of dentin through cavity size reduction improves the fracture resistance of teeth $(25,26,27)$. Specifically, removal of cervical dentin, such as associated with TEC, increases cuspal deflection which may enhance the potential for fracture (27), even though it does not significantly alter the stiffness of the tooth (27). The loss of cervical dentin has also been 
associated with increased frequency and severity of cuspal fracture as observed clinically (28).

Fracture predilection is one of the key factors determining the fate of root-filled teeth. An estimated $4.6 \%$ to $7.5 \%$ of root-filled teeth, predominantly molars and premolars, are extracted within 4 to 5 years post-treatment $(9,29)$ and up to $47 \%$ of post-treatment extractions are due to coronal fractures $(6,7,30)$. Frequently attributed to pronounced loss of dental tissues (7), this reality has been frustrating to patients and clinicians alike. Indeed, the reported survival of root-filled molars without crowns at 1, 2 and 5 years post-treatment is $96 \%, 88 \%$ and $36 \%$, respectively (8); however, the 5-year survival increases to $78 \%$ for molars with maximum coronal tooth structure remaining (8). Our findings suggested that in the mandibular premolars and molars, the CEC design improved resistance to fracture and, in the premolars, allowed cuspal chipping patterns that would be easier to restore clinically than the full cuspal fractures observed in the premolars with TEC. Thus, CEC conveyed a benefit in the molars and premolars in that it might diminish the susceptibility of those teeth to catastrophic fracture in the long-term after treatment. In the premolars, the most prone to fracture after endodontic treatment (31), this benefit was not offset by apparent risks of compromised instrumentation, suggesting that CEC should merit consideration as a standard cavity design. In the molars, the benefit must be weighed against the risk of compromised canal instrumentation in the distal canals, which may compromise the prognosis of healing. While the impact of compromised instrumentation on prognosis of healing is yet to be investigated, a modest widening of the distal outline of CEC to better debride the ovalshaped distal canal (18) might reduce this risk. Therefore, even in molars, CEC should 
merit consideration as a preferable cavity design. In contrast to the premolars and molars, our results did not support the notion of CEC in the anterior teeth.

Many areas of healthcare, including dentistry (21), have been moving towards minimally invasive procedures that may benefit the patients. While critical technological advances such as operating microscopes and nickel-titanium instruments have enabled this progress, the clinicians have to adapt their skills to face the challenge of working effectively in a confined space (32). Performing root canal treatment through CEC is likely to benefit patients, but it challenges the clinician to address all canals, debride all pulp tissue from remaining pulp horns and avoid procedural complications while working through a restrictive cavity without "convenience form". Individual skilled clinicians have already met this challenge (10-12) suggesting the practicality of CEC. It may be appropriate for the specialty of endodontics to revisit the principles of endodontic access cavities in premolars and molars to make them more in line with CEC.

In conclusion, coronal dentin was conserved in incisors, premolars and molars when accessed through $\mathrm{CEC}$. The dentin conservation afforded an increased resistance to fracture in the mandibular molars and premolars, but it also compromised the efficacy of canal instrumentation in the distal canals of the molars. These results appeared to support the rationale for revision of the guidelines of endodontic cavity design in premolars and molars, focused on conservation of coronal dentin. 


\section{References}

1. Ingle JI. Endodontic cavity preparation. In: Ingle J, Tamber J, editors. Endodontics. Third ed. Philadelphia: Lea \& Febiger; 1985. p. 102-167.

2. Patel S, Rhodes J. A practical guide to endodontic access cavity preparation in molar teeth. Brit Dent J. 2007;203:133-40.

3. Ree M, Schwartz RS. The endo-restorative interface: Current concepts. Dent Clin North Am. 2010;54:345-74.

4. Kishen A. Mechanisms and risk factors for fracture predilection in endodontically treated teeth. Endodontic Topics. 2006;13:57-83.

5. Tang W, Wu Y, Smales RJ. Identifying and reducing risks for potential fractures in endodontically treated teeth. J Endod. 2010;36:609-17.

6. Vire DE. Failure of endodontically treated teeth: Classification and evaluation. J Endod. 1991;17:338-42.

7. Tzimpoulas NE, Alisafis MG, Tzanetakis GN, Kontakiotis EG. A prospective study of the extraction and retention incidence of endodontically treated teeth with uncertain prognosis after endodontic referral. J Endod. 2012;38:1326-9.

8. Nagasiri R, Chitmongkolsuk S. Long-term survival of endodontically treated molars without crown coverage: A retrospective cohort study. J Prosthet Dent. 2005;93:164-70.

9. Chen S, Chueh L, Hsiao CK, Wu H, Chiang C. First untoward events and reasons for tooth extraction after nonsurgical endodontic treatment in taiwan. J Endod. 2008;34:6714.

10. Clark D, Khademi J. Modern molar endodontic access and directed dentin conservation. Dent Clin North Am. 2010;54:249-73.

11. Clark D, Khademi JA. Case studies in modern molar endodontic access and directed dentin conservation. Dent Clin North Am. 2010;54:275-89.

12. Boveda C. Personal communication. http://www.carlosboveda.com/casosclinicos.htm

13. Swain MV, Xue J. State of the art of micro-CT applications in dental research. Int J Oral Sci. 2009;1:177-88.

14. Peters OA, Schonenberger K, Laib A. Effects of four ni-ti preparation techniques on root canal geometry assessed by micro computed tomography. Int Endod J. 2001;34:22130. 
15. Peters OA, Laib A, Gohring TN, Barbakow F. Changes in root canal geometry after preparation assessed by high-resolution computed tomography. J Endod. 2001;27:1-6.

16. Peters OA, Peters CI, Schonenberger K, Barbakow F. ProTaper rotary root canal preparation: Effects of canal anatomy on final shape analysed by micro CT. Int Endod J. 2003;36:86-92.

17. Paqué F, Ganahl D, Peters OA. Effects of root canal preparation on apical geometry assessed by micro-computed tomography. J Endod. 2009;35:1056-9.

18. Paqué F, Balmer M, Attin T, Peters OA. Preparation of oval-shaped root canals in mandibular molars using nickel-titanium rotary instruments: A micro-computed tomography study. J Endod. 2010;36:703-7.

19. Assif D, Nissan J, Gafni Y, Gordon M. Assessment of the resistance to fracture of endodontically treated molars restored with amalgam. J Prosthet Dent. 2003;89:462-5.

20. Cobankara FK, Unlu N, Cetin AR, Ozkan HB. The effect of different restoration techniques on the fracture resistance of endodontically-treated molars. Oper Dent. 2008;33:526-33.

21. Murdoch-Kinch CA, McLean ME. Minimally invasive dentistry. J Am Dent Assoc. 2003;134:87-95.

22. Plotino G, Grande NM, Testarelli L, Gambarini G. Cyclic fatigue of Reciproc and WaveOne reciprocating instruments. Int Endod J. 2012;45:614-8.

23. Pirani C, Ruggeri O, Cirulli PP, Pelliccioni GA, Gandolfi MG, Prati C. Metallurgical analysis and fatigue resistance of WaveOne and ProTaper nickel-titanium instruments. Odontology. 2013:1-6.

24. Wu MK, R'oris A, Barkis D, Wesselink PR. Prevalence and extent of long oval canals in the apical third. Oral Surg Oral Med Oral Pathol Oral Radiol Endod. 2000;89:739-43.

25. Al-Omiri MK, Al-Wahadni AM. An ex vivo study of the effects of retained coronal dentine on the strength of teeth restored with composite core and different post and core systems. Int Endod J. 2006;39:890-9.

26. Reeh ES, Messer HH, Douglas WH. Reduction in tooth stiffness as a result of endodontic and restorative procedures. J Endod. 1989;15:512-6.

27. Panitvisai P, Messer HH. Cuspal deflection in molars in relation to endodontic and restorative procedures. J Endod 1995;21:57-61. 
28. Hansen EK, Asmussen E. Cusp fracture of endodontically treated posterior teeth restored with amalgam: teeth restored in Denmark before 1975 versus after 1979. Acta Odontol Scand 1993;51:73-7.

29. Ng YL, Mann V, Gulabivala K. A prospective study of the factors affecting outcomes of non-surgical root canal treatment: Part 2: Tooth survival. Int Endod J. 2011;44:610-25.

30. Touré B, Faye B, Kane AW, Lo CM, Niang B, Boucher Y. Analysis of reasons for extraction of endodontically treated teeth: A prospective study. J Endod. 2011;37:15125.

31. Hansen EK, Asmussen E, Christiansen NC. In vivo fractures of endodontically treated posterior teeth restored with amalgam. Endod Dent Traumatol. 1990;6:49-55.

32. Lamata P. Ali W, Cano A, Cornella J, Declerck J, et al. Augmented reality for minimally invasive surgery: Overview and some recent advances. In: Maad S, editor. Augmented Reality. ISBN: 978-953-7619-69-5. InTech, Available from:

http://www.intechopen.com/books/augmented-reality/augmented-reality-for-minimallyinvasive-surgery- overview-and-some-recent-advances 


\section{Legend to Figures}

Figure 1. A typical outline of a conservative endodontic cavity (CEC) in a mandibular first molar. For comparison purposes, the outline of a traditional endodontic cavity (TEC) is demarcated with a dotted line.

Figure 2. Merged pre-treatment (green) and post-treatment (red) micro-CT images of maxillary central incisors (mesial view) where root canals were accessed and instrumented through CEC (A) and TEC (B).

Figure 3. Merged pre-treatment (green) and post-treatment (red) micro-CT images of a mandibular first molar where root canals were accessed and instrumented through CEC from buccal view (A), distal view (B), lingual view (C), and mesial view (D).

Figure 4. Typical fracture patterns in mandibular second premolars with CEC (A) and TEC (B), loaded to fracture in the Instron Universal machine. Note the small cavity outline and superficial cuspal chipping typical of premolars with CEC and the wall fracture typical of premolars with TEC. 
Fig. 1.

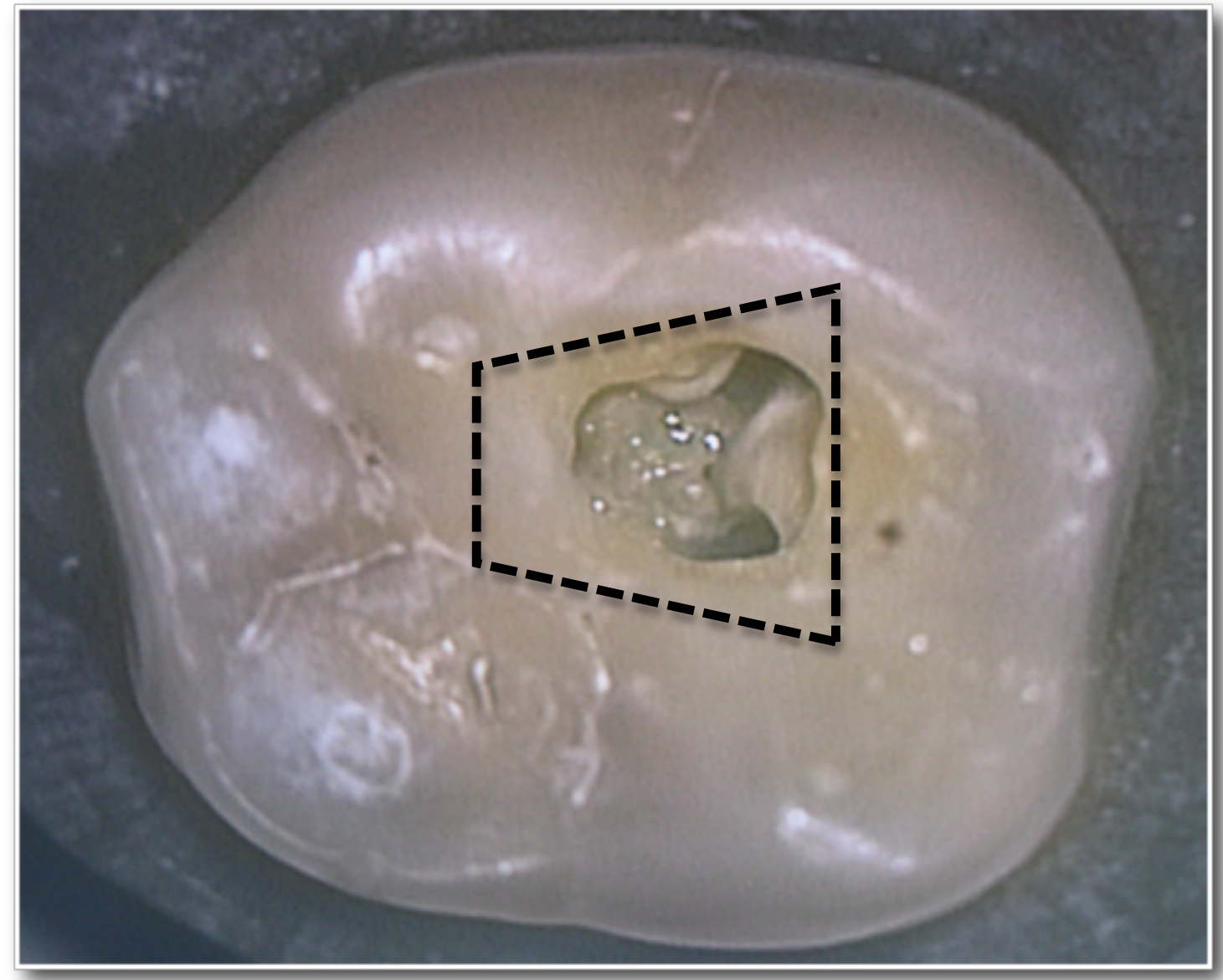


Fig. 2

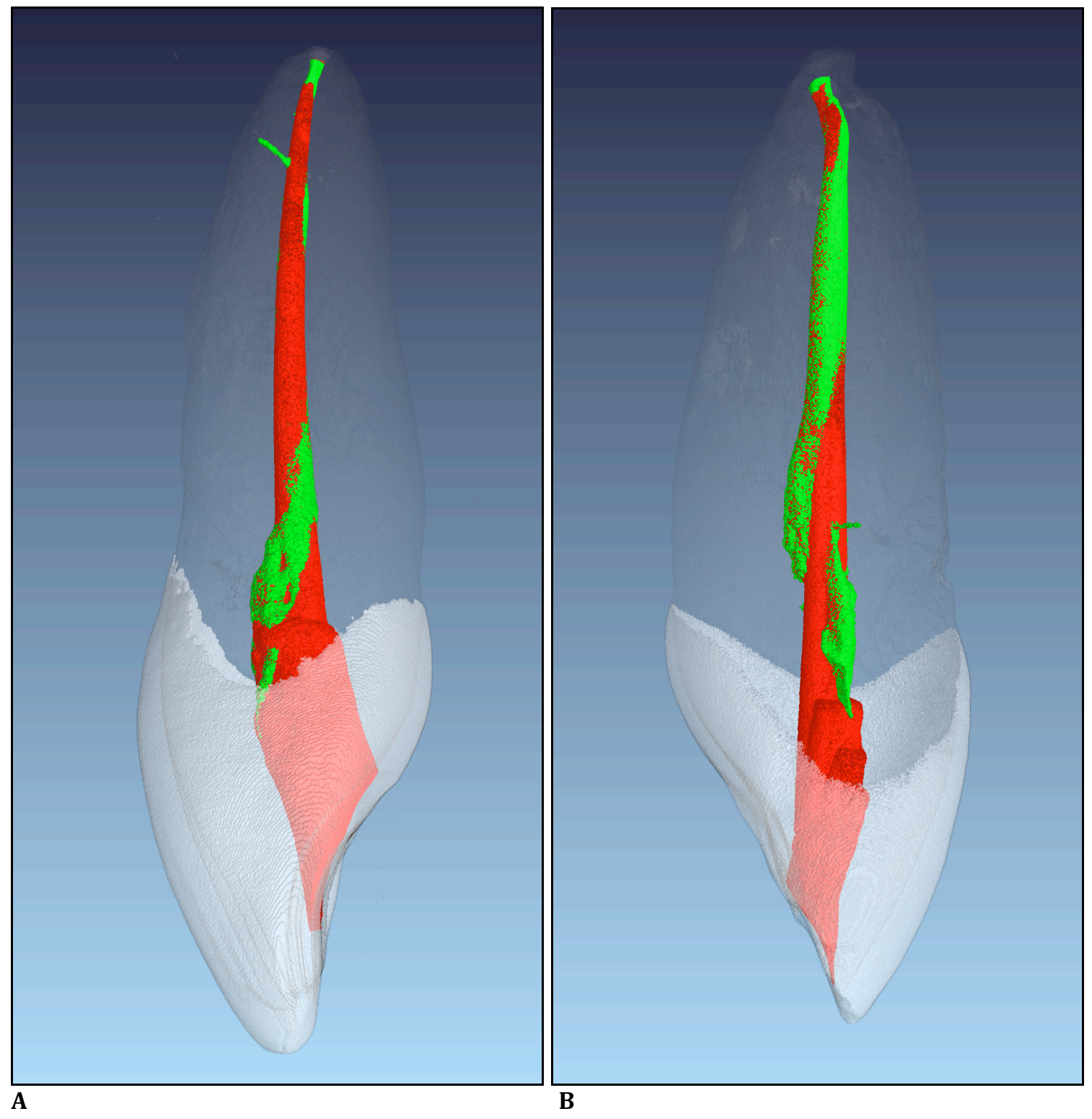


Fig. 3
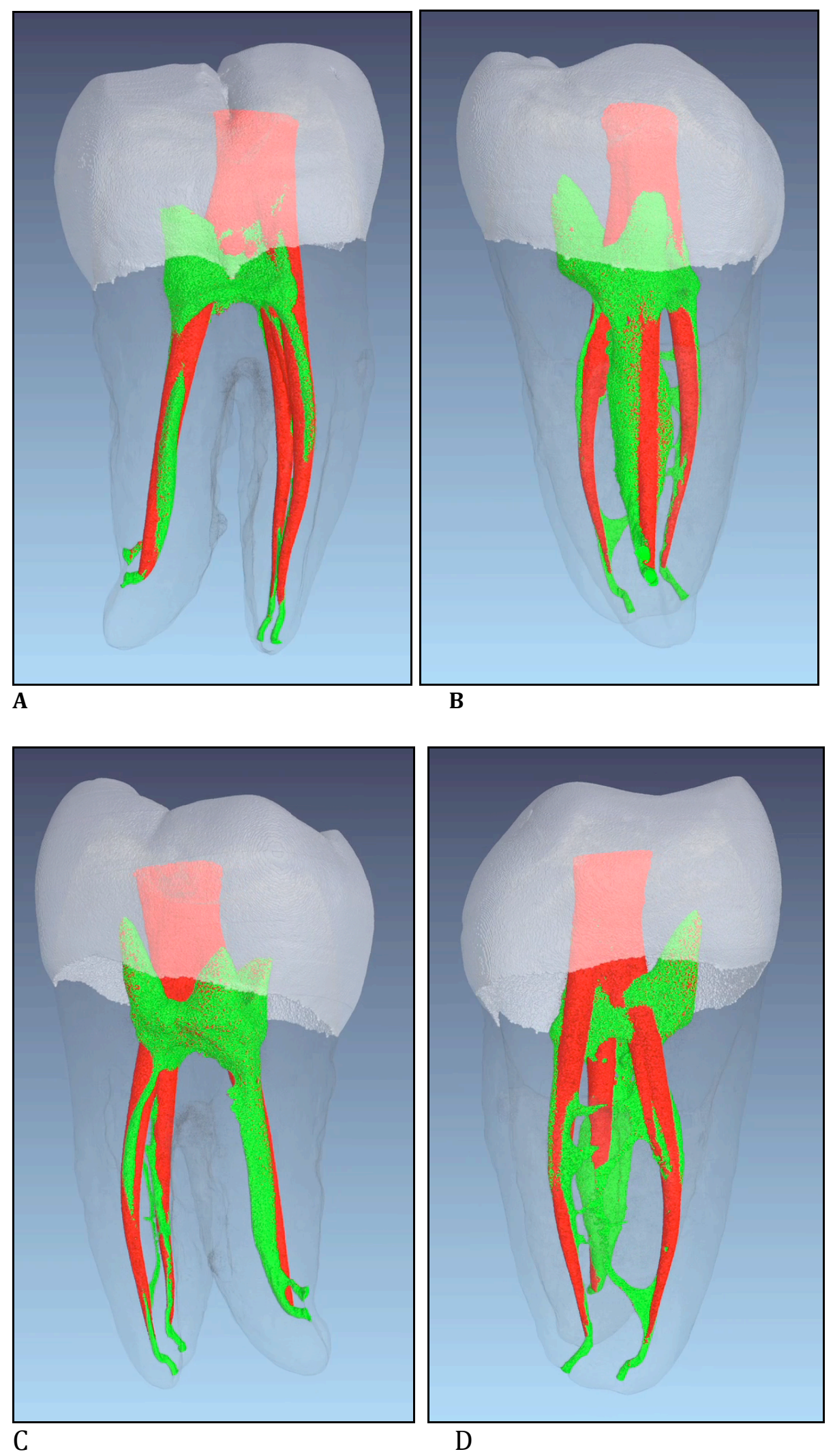
Fig. 4.

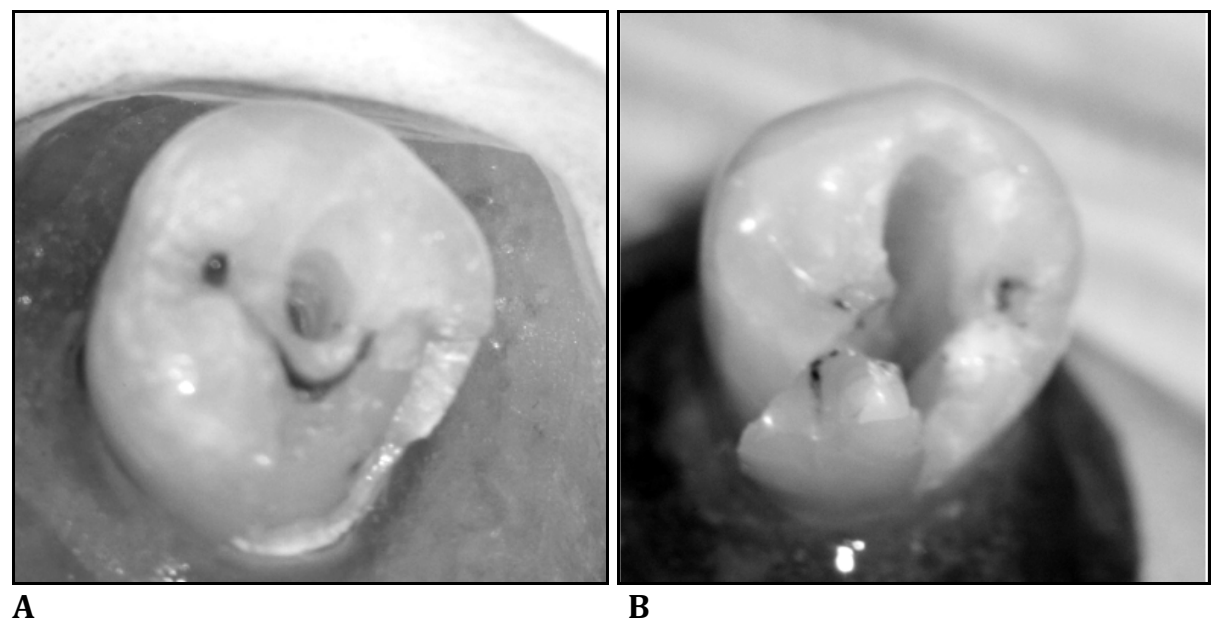




\section{Tables}

Table 1. Canal wall area untouched by instruments during instrumentation performed through conservative (CEC) or traditional (TEC) endodontic cavities, assessed by micro$\mathrm{CT}$. The untouched area is expressed as proportion of the total canal wall area (mean and standard deviation).

\begin{tabular}{|l|l|c|c|c|}
\hline \multirow{2}{*}{$\begin{array}{c}\text { Tooth type } \\
(\mathrm{n}=10)\end{array}$} & Assessed canal level & \multicolumn{2}{c|}{$\begin{array}{c}\text { Untouched canal wall area } \\
(\% \text { of total canal wall surface })\end{array}$} & \\
\cline { 3 - 4 } & & P value \\
\hline Incisors & Coronal third & $54.3 \pm 8.7$ & $56.3 \pm 8.7$ & 0.613 \\
& Middle third & $55.4 \pm 25.7$ & $54.3 \pm 26.0$ & 0.925 \\
& Apical third & $75.1 \pm 18.8$ & $56.6 \pm 29.8$ & 0.114 \\
& Total canal & $60.1 \pm 19.1$ & $45.5 \pm 15.4$ & 0.070 \\
\hline Premolars & Coronal third & $46.7 \pm 18.2$ & $44.7 \pm 11.0$ & 0.769 \\
& Middle third & $43.6 \pm 24.3$ & $41.5 \pm 28.7$ & 0.860 \\
& Apical third & $61.0 \pm 23.7$ & $71.7 \pm 17.6$ & 0.267 \\
& Total canal & $63.7 \pm 22.2$ & $76.1 \pm 17.3$ & 0.181 \\
\hline Molars & Coronal third & $37.8 \pm 12.9$ & $32.2 \pm 12.1$ & 0.329 \\
mesial canals & Middle third & $25.2 \pm 10.9$ & $26.4 \pm 16.0$ & 0.846 \\
& Apical third & $36.8 \pm 10.0$ & $35.5 \pm 10.0$ & 0.741 \\
& Total canal & $47.6 \pm 21.1$ & $47.7 \pm 10.4$ & 0.990 \\
\hline Molars & Coronal third & $47.6 \pm 16.8$ & $35.6 \pm 47.6$ & 0.117 \\
distal canals & Middle third & $49.3 \pm 15.0$ & $45.0 \pm 15.0$ & 0.530 \\
& Apical third & $\mathbf{5 7 . 3} \pm \mathbf{2 1 . 8}$ & $\mathbf{3 9 . 5} \pm \mathbf{1 5 . 2}$ & $\mathbf{0 . 0 4 8}$ \\
& Total canal & $\mathbf{5 7 . 2} \pm \mathbf{2 1 . 7}$ & $\mathbf{3 6 . 7} \pm \mathbf{1 7 . 2}$ & $\mathbf{0 . 0 3 2}$ \\
\hline
\end{tabular}


Table 2. Dentin volume removed (mean and standard deviation) by preparation of conservative (CEC) or traditional (TEC) endodontic cavities and root canal instrumentation in extracted teeth, assessed by micro-CT.

\begin{tabular}{|c|c|c|c|c|}
\hline \multirow{2}{*}{$\begin{array}{l}\text { Tooth type } \\
(\mathrm{n}=10)\end{array}$} & \multirow{2}{*}{ Assessed level } & \multicolumn{2}{|c|}{ Dentin volume removed $\left(\mathrm{mm}^{3}\right)$} & \multirow{2}{*}{$\mathrm{P}$ value } \\
\hline & & CEC & TEC & \\
\hline \multirow[t]{5}{*}{ Incisors } & Crown level & $14.13 \pm 4.21$ & $20.78 \pm 3.15$ & 0.0012 \\
\hline & Canal coronal $1 / 3$ & $1.02 \pm 0.45$ & $1.38 \pm 0.65$ & 0.167 \\
\hline & Canal middle $1 / 3$ & $0.66 \pm 0.44$ & $0.63 \pm 0.47$ & 0.885 \\
\hline & Canal apical 1/3 & $0.18 \pm 0.13$ & $0.29 \pm 0.26$ & 0.247 \\
\hline & Total & $16.09 \pm 4.66$ & $23.24 \pm 3.38$ & 0.0014 \\
\hline \multirow[t]{5}{*}{ Premolars } & Crown level & $5.82 \pm 1.32$ & $11.93 \pm 4.17$ & 0.0016 \\
\hline & Canal coronal $1 / 3$ & $1.55 \pm 0.33$ & $1.90 \pm 0.56$ & 0.106 \\
\hline & Canal middle $1 / 3$ & $0.73 \pm 0.32$ & $0.58 \pm 0.26$ & 0.265 \\
\hline & Canal apical 1/3 & $0.23 \pm 0.17$ & $0.13 \pm 0.07$ & 0.1026 \\
\hline & Total & $8.24 \pm 1.64$ & $14.59 \pm 4.85$ & 0.0024 \\
\hline \multirow[t]{5}{*}{ Molars } & Crown level & $25.45 \pm 5.83$ & $60.22 \pm 12.64$ & $<0.0001$ \\
\hline & Canal coronal $1 / 3 *$ & $4.60 \pm 1.08$ & $4.34 \pm 1.10$ & 0.600 \\
\hline & Canal middle $1 / 3 *$ & $2.44 \pm 0.73$ & $2.46 \pm 0.73$ & 0.952 \\
\hline & Canal apical $1 / 3 *$ & $0.57 \pm 0.25$ & $0.48 \pm 0.24$ & 0.422 \\
\hline & Total* & $33.37 \pm 6.41$ & $67.71 \pm 14.12$ & $<0.0001$ \\
\hline
\end{tabular}

* The sum of the three canals 
Table 3. Load-at-fracture (mean and standard deviation) for extracted teeth with conservative (CEC), traditional (TEC) or no endodontic cavities (negative control), assessed in the Instron Universal machine. Similar letter case designation indicates nonsignificant differences; different letter case designations indicate a significant difference $(\mathrm{p}<0.05)$.

\begin{tabular}{|l|c|c|c|}
\hline \multirow{2}{*}{$\begin{array}{l}\text { Tooth type } \\
(\mathrm{n}=10)\end{array}$} & \multicolumn{3}{|c|}{ Load-at-fracture (N) } \\
\cline { 2 - 4 } & CEC & TEC & Control $^{\mathrm{a}}$ \\
\hline Incisors & $1134.6 \pm 109.2^{\mathrm{a}}$ & $1305.2 \pm 97.6^{\mathrm{a}}$ & $1276.6 \pm 93.8^{\mathrm{a}}$ \\
\hline Premolars & $586.8 \pm 116.9^{\mathrm{b}}$ & $328.4 \pm 56.7^{\mathrm{B}}$ & $634.4 \pm 58.6^{\mathrm{b}}$ \\
\hline Molars & $1586.9 \pm 196.8^{\mathrm{d}}$ & $641.7 \pm 62.0^{\mathrm{D}}$ & $2029.1 \pm 259.7^{\mathrm{d}}$ \\
\hline
\end{tabular}




\section{DISCUSSION}

Dental treatment in general, including endodontic treatment, is intended to eliminate disease and help patients maintain a functional dentition. One risk to which teeth are exposed after endodontic treatment is fracture, reported in 20 to $62 \%$ of teeth over a period of 10 to 20 years (99-101). While frequently fractured teeth may be restored back to function, a reported 15 to $25 \%$ of fractured teeth are extracted $(75,76,102)$ primarily because they are non-restorable. Thus, the susceptibility of teeth to fracture should be a consideration when endodontic treatment protocols are established. Several factors that govern the susceptibility of root-filled teeth to fracture may not be fully controlled, making it critically important for clinicians to identify and prioritize those factors that are within their control. One of these factors is the extent of the endodontic access cavity. Recent publications $(26,27)$ have highlighted the possibility to perform endodontic treatment through a conservative endodontic cavity (CEC) and proposed that this approach might decrease the susceptibility of the treated teeth to fracture, although CEC may compromise adequate instrumentation of the canals. This study was undertaken to assess the resistance to fracture of teeth with CEC and also the instrumentation efficacy when treatment is carried out through the restricted access afforded by CEC.

Maxillary central incisors, mandibular second premolars and mandibular first molars were studied to explore the risks and benefits of CEC in the three main tooth types. While each tooth within the dentition has specific characteristics, the limited availability of extracted human mature, non-carious teeth precluded expansion of the study to include all teeth in the dentition. The specific anatomy of every tooth notwithstanding, within each tooth type - anteriors (incisors and canines), premolars and molars - the relative 
morphology of tooth crowns and pulp chambers has been reported to be fairly consistent (24), suggesting that the teeth studied could be considered representative of the whole dentition. Within each tooth type, teeth were matched for length and canal curvature to minimize variation among test and control groups.

The sample size was calculated based on previous studies on instrumentation efficacy $(55,56,58,103,104)$. It was set at 10 teeth/type/group, to detect differences in the untouched canal wall area between the experimental (CEC) and control (TEC) groups of $12 \%$ in the anteriors and premolars and $23 \%$ in the molars. The actual differentials observed were about $15 \%$ and $12 \%$ in the anteriors and premolars, respectively, and 0 and $20 \%$ in the molar mesial and distal canals, respectively, matching the assumptions made in the power calculation. The sample size for the fracture experiment was not calculated due to the lack of data in the literature on a similar study design. Yet, the significant differences observed between the CEC and TEC groups, as well as between the TEC and negative control groups, suggested that the analysis was performed with adequate power.

The resistance to fracture of root-filled teeth is a particular concern, because their remaining tooth structure is compromised rendering them susceptible to fracture $(69,79$, 87). In vitro testing of the fracture resistance of teeth is an imperative step in devising treatment protocols aimed at reducing the risk of post-treatment fracture. In order to minimize bias and confounding factors that may affect the fracture resistance, several precautions were included in the study design. The endodontic cavity preparation and canal instrumentation were standardized throughout the study, being performed by one operator (RK). Standardization is critical when the sample size is minimal and an 
innovative technique is studied that requires attention to detail. Testing of fracture was carried out in a blinded manner to minimize bias. During canal instrumentation, only $\mathrm{NaOCl}$ was used for irrigation to avoid the potential impact of different irrigation solutions on dentin removal and fracture resistance as suggested in several previous studies (105-108). The teeth were loaded without restoration of the endodontic cavities to avoid the confounding effects of enamel and dentin bonding restorative materials. In this manner, the effect of dentin loss on the structural integrity of the tooth could be isolated and directly assessed. While the testing of unrestored teeth did not simulate common clinical realities, it permitted observations of the relationship between dentin removal and fracture resistance.

The compressive load-at-fracture was tested in a static mode, as in many previous studies $(71,74,109,110)$. Although the use of cyclic loading has been suggested to better simulate clinical function of teeth (67), cyclic loading of unrestored teeth often leads to premature cuspal fracture due to repeated unsupported cuspal flexure (73). Thus, cyclic loading was considered undesirable for assessing the fracture resistance of specimens in this study.

Micro-CT is a well-validated $(55,56,58,103,104)$ method for evaluating different aspects of root canal preparation, including the canal wall surface that is touched or untouched by the instruments and the volume of dentin removed at any desired level of the tooth and canal. The most important features of micro-CT are its non-destructive nature and its quantitative accuracy, compared to alternative assessment methods that require sectioning of the specimens $(33,51,52,54,63-65)$. Although CBCT is used clinically as reference for plotting CEC for treated teeth (111), its lower resolution (62) 
suggested it would be less suitable than micro-CT for assessing the efficacy of canal instrumentation and the volume of dentin removed in this study.

The proportion of untouched canal wall surface observed in this study was well within the range reported elsewhere using micro-CT assessment of similar tooth types $(14,59$, $60,103,112)$. The proportion of untouched canal wall surface was expected to be significantly higher in teeth with CEC in the three tooth types. However, analysis of the reconstructed micro-CT images revealed that the proportion of untouched canal wall surface was significantly higher only in the distal canals of the molars with CEC but not in the anteriors, premolars and the molar mesial canals. Moreover, when analyzed at three canal levels, the only significant difference was again seen in the apical level of the distal canals of molars with CEC. The compromised instrumentation efficacy observed in the distal canals of mandibular molars with CEC was attributed to the oval cross-section in the apical third, reported in 25 to $30 \%$ of mandibular molars (113). Because of the round cross-section of conventional root canal instruments, they do not consistently reach the recesses in oval-shaped canals (113). Thus, instrumentation of oval-shaped root canals in general, and in the distal roots of mandibular molars in particular, is regarded a major challenge with reports of 44 to $79 \%$ of canal wall surface remaining untouched regardless of the instrumentation technique $(59,114)$. Notably, the overall untouched canal wall surface in the distal canals of mandibular molars with CEC $(57.2 \pm 21.7 \%)$ was still within the previously reported $(59,114)$ range, suggesting that although the efficacy of canal instrumentation through CEC was impaired, it was still at par with reports for canals instrumented elsewhere through TEC. Altering the preparation protocol in the distal canals of the molars, approaching them as two separate canals, was suggested to 
improve the efficacy of instrumentation in those canals (59). By not using this approach in the present study, the outcomes might have been biased towards larger than usual proportions of untouched canal walls in the molar distal canals, especially in the CEC group. It is noteworthy that to date, the only root canal instrument shown to improve the ability to contact walls in oval canals of mandibular molars is the Self-Adjusting-File (SAF) (ReDent Nova, Ra'anana, Israel) (115). Although this instrument was not used in the present study, it could be potentially used in conjunction with CEC. Whether or not this will improve the outcomes requires independent investigation.

Root canal instrumentation, a key step in endodontic therapy, is primarily concerned with effective debridement of pulp tissue, removal of wall-adhering biofilms and a zone of microbe-invaded dentin peripheral to the canal lumen, so as to disinfect the root canal space (14-19). It should be noted that while instrumentation effectively reduces the microbial load (18), its degree of efficacy has not been well correlated with the prognosis for healing. Therefore, although the distal canals of mandibular molars with CEC show a higher percentage of untouched canal wall area, the improved fracture resistance obtained with CEC compared to TEC is an advantage that should be taken into account when assessing teeth for endodontic treatment.

Dentin removal was expected to be less in teeth with CEC compared with those with the conventional TEC. Indeed, the analysis of micro-CT reconstructed images revealed that the volume of dentin removed was significantly smaller in the teeth with CEC in the three tooth types. As expected, most of the dentin conserved in all tooth types was at the crown level, while dentin removal at any of the canal levels was comparable in teeth with CEC and TEC. This pattern of dentin conservation was in accordance with the suggestion that 
pericervical dentin ( $4 \mathrm{~mm}$ below and above the level of crestal bone) should be preferentially conserved to buttress the teeth (26). It also suggested that the endodontic cavity design did not impact much upon the amount of dentin removed along the root canals and on the ability of the instruments to remain fairly centered within the canal lumen. This, in part, could be attributed to the use of WaveOne instruments, shown to remain well centered even when used in very curved root canals (107).

The resistance to fracture was expected to be significantly higher in the CEC group than in the TEC group and significantly lower for both groups than for the negative control. The fracture resistance was indeed higher in the molars and premolars with CEC, but not in the anteriors with CEC when compared with TEC. In the anterior teeth, the fracture resistance was comparable for the CEC, TEC and negative control groups, suggesting that the endodontic cavities did not predispose these teeth to fracture under loads such as applied in this study. Indeed, it has been suggested that the force required to fracture endodontically accessed and instrumented canines was only $2 \%$ lower than for nonaccessed matched pairs (78). Conversely, the fracture resistance in the premolars and molars with TEC was lower than in the negative controls, suggesting that the traditional endodontic cavity could play a role in predisposing those teeth to fracture. Indeed, it has been suggested that the force required to fracture endodontically accessed and instrumented premolars was $30 \%$ lower than that required to fracture their non-accessed matched pairs (78). On the other hand, when the molars and premolars in the present study were accessed through CEC, their fracture resistance was increased to levels comparable to the negative controls even though they were not restored. This suggests that CEC has the potential to mitigate the predilection to fracture of molars and 
premolars. Thus, the minimally invasive CEC confers an advantage to molars and premolars in that their ability to withstand functional loads is close to that of intact teeth.

The propensity of root-filled teeth to fracture is not related to biomechanical properties (including hardness and toughness) of the remaining dentin after treatment (21). Rather, it is the amount of remaining dentin that most critically impacts on the fracture predilection of root-filled teeth $(69,79,97)$. Indeed, in the present study less dentin removal was associated with better resistance to fracture, as shown in molars and premolars with CEC compared to similar teeth with TEC. The dentin conservation differential between CEC and TEC was greatest in the molars, followed by the premolars and anteriors. Similarly, the fracture resistance differential between CEC and TEC was greatest in the molars and less in the premolars, but it was none in the anteriors. Thus, even though dentin removal was associated with fracture resistance above a certain threshold, the lack of difference in fracture resistance in the anterior teeth, in spite of a significant difference in dentin removal, suggested that measurement of dentin removal per se should not be considered the only surrogate outcome for the fracture resistance of teeth.

Predilection for fracture is one of the key factors determining the fate of root-filled teeth. When root-filled teeth were followed-up for 10 years, cusp fractures occurred in approximately $55 \%$ of those restored with amalgam and $20 \%$ of those restored with composite resins, compared to approximately $2 \%$ cusp fractures in non-endodontically treated teeth restored with amalgam (116). Furthermore, as about $24 \%$ of fractures extend below the gingival margin (102), the affected teeth often require complex restorative solutions and may be extracted. Indeed, an estimated 4 to $8 \%$ of root-filled teeth, primarily molars and premolars, are extracted within 4 to 5 years after treatment $(95$, 
117 ) and up to $47 \%$ of post-endodontic treatment extractions are due to coronal fractures (96-98). Having to face repeated restorative challenges and possible tooth loss over the years frustrates patients and clinicians alike and erodes their confidence in the ability of root-filled teeth to survive for many years after treatment $(26,79)$. The reported survival of root-filled molars without crowns at 1,2 and 5 years post-treatment is $96 \%, 88 \%$ and $36 \%$, respectively (118); however, the 5 -year survival is $78 \%$ for molars with maximum coronal tooth structure remaining (118), suggesting that the survival of root-filled teeth is also related to conservation of coronal tooth structure. It is conceivable that with wider adoption of the CEC concept within the profession, the erosion in the confidence of clinicians in endodontic treatment may be stemmed.

A universal concept in healthcare is the consideration of benefits and risks to suggest which interventions are preferred. Like all interventions, endodontic access cavity designs also should be subjected to assessment of associated benefits and risks. In the anterior teeth, neither a benefit nor a risk was evident in association with CEC, as the fracture resistance and instrumentation efficacy were not impacted. In the absence of benefits, CEC may not be supported as a standard cavity design because it is more intricate, labour intensive and operator sensitive than the common TEC. In the premolars, the improved fracture resistance shown with CEC, which may in turn improve the survival of these teeth, is an important benefit. The pattern of cusp chipping is also a benefit, as chipped cusps would be easier to restore clinically than the fully fractured cusps observed in the premolars with TEC. There was no evident risk associated with $\mathrm{CEC}$ as the instrumentation efficacy was not impacted. This analysis suggests that CEC should merit consideration as a desirable cavity design in premolar teeth. In the molars, 
the improved fracture resistance shown with CEC is an important benefit, especially because fractured molars more frequently require extraction than other tooth types (96). There is, however, the risk to consider of compromised instrumentation efficacy in the distal canals which may compromise the prognosis of healing. While this risk cannot as yet be quantified, because the impact of compromised instrumentation on healing has not been determined, the potential benefit of an improved resistance to fracture with CEC is evident. Also, the deficit in instrumentation efficacy may be mitigated by treating the distal canal as two separate buccal and lingual pathways (59), or by mildly expanding the CEC outline at the distal aspect. Taking all the above considerations into account, the benefits of CEC in molars appear to outweigh the risks, suggesting that even in molars CEC should merit consideration as a preferable cavity design.

Minimally invasive dentistry has been defined as the application of "a systematic respect for the original tissue" to benefit the patient; it recognizes that an artifact is of less biological value than the original healthy tissue $(3,4)$. This concept is critically hinged on advances in science that facilitate an evolution through emerging technologies (5). Although this paradigm's conception was within restorative dentistry, its application and principles can be applied to other aspects of dentistry (4). Based on the aforementioned principles, it is clear that CEC satisfies both the concept and ideology of minimally invasive dentistry in that it seeks to preserve the original healthy tissue (dentin) to the greatest extent possible in an attempt to maximize the survival of the tooth and limit the need for replacement of function through artifacts (restorative materials or implant). While emerging technologies of magnification, illumination and reciprocating rotational instrumentation facilitate the application of CEC, the clinician's skill and knowledge 
remain the most important elements (5). It is with regards to the latter that the profession should distinguish itself, because CEC is technically challenging and may be readily disregarded as the constraints of time and training weigh on the clinician. As in other minimally invasive procedures across healthcare, the clinicians have to adapt their skills to face the challenge of working effectively in a confined space (119). If more dentists opt for the CEC cavity design, especially in molars and premolars, dentistry could improve the public's perception of its professionalism and honesty (6).

The next phase of this research project is the construction of finite element analysis models. Finite element modeling involves a structure, such as a tooth with an endodontic cavity, that is divided into a number of small simple-shaped elements for which individual deformation (strain and stress) can be more easily calculated than for the whole structure (120). Calculation of the deformation of all the elements simultaneously allows the deformation of the whole structure to be assessed (120). The finite element method is a numerical procedure used for analyzing structures and consists of a computer model of a material or design that is stressed and analyzed for specific results. It has been employed to assess stress-strain distributions within teeth under occlusal loads (121). Regions of stress-strain concentration are interpreted as potentiators of crack initiation and propagation (122). This method lends itself to simulation of different loads applied to the tooth structure, both static and dynamic, as well as different types of restorations present. The relative variation in the data between different tooth types and access cavity designs with varying restorations can then be interpreted and analyzed to gain further insight into the concept of minimally invasive dentistry as applied to endodontics and perhaps lead to a predictive model. 


\section{CONCLUSIONS}

Within the limitations of this in vitro study, coronal dentin was conserved in incisors, premolars and molars when accessed through CEC. The dentin conservation afforded an increased resistance to fracture in the mandibular molars and premolars but not in the maxillary incisors. It also compromised the efficacy of canal instrumentation in the distal canals of the molars, specifically at the apical third of the canal. These results supported the rationale for revision of the guidelines of endodontic cavity design in molars and premolars, focused on conservation of coronal dentin. 


\section{REFERENCES}

\section{References}

1. Black G. Operative dentistry. 7th ed. Black G, editor. Chicago: Medico-Dental Publishing; 1936.

2. Sigurjons H. "Extension for prevention": Historical development and current status of G V black's concept. Oper Dent. 1983;8(2):57-63.

3. Ericson D. The concept of minimally invasive dentistry. Dent Update. 2007;34:9,10, 12-14, 17-18.

4. Ericson D. What is minimally invasive dentistry? Oral Health Prev Dent. 2004;2 Suppl 1:287-92.

5. Murdoch-Kinch CA, McLean ME. Minimally invasive dentistry. J Am Dent Assoc. 2003;134:87-95.

6. Christensen. The advantages of minimally invasive dentistry. J Am Dent Assoc. 2005;136:1563-5.

7. Nair PNR. Pathogenesis of apical periodontitis and the causes of endodontic failures. Crit Rev Oral Biol Med. 2004;15:348-81.

8. Kakehashi S, Stanley HR, Fitzgerald RJ. The effects of surgical exposures of dental pulps in germ-free and conventional laboratory rats. Oral Surg Oral Med Oral Pathol. 1965;20:340-9.

9. Bergenholtz G. Micro organisms from necrotic pulp of traumatized teeth. ODONT REVY. 1974;25:347-58.

10. Moller AJR, Fabricius L, Dahlen G, Ohman AE, Heyden G. Influence on periapical tissues of indigenous oral bacteria and necrotic pulp tissue in monkeys. Scand J Dent Res. 1981;89:475-84.

11. Sundqvist G. Bacteriological studies of necrotic dental pulps.[dissertation]. ; 1976.

12. Stashenko P. Etiology and pathogenesis of pulpitis and apical periodontitis. In:

Orstavik D, Pitt Ford T, editors. Essential endodontology. Prevention and treatment of apical periodontitis. 1st ed. Oxford, Great Britain: Blackwell Science Publications; 1998. p. 42-67.

13. Ørstavik D, Pitt Ford T. Apical periodontitis; microbial infection and host responses. In: Ørstavik D, Pitt Ford T, editors. Essential endodontology. Prevention and treatment of 
apical periodontitis. 1st ed. Oxford, Great Britain: Blackwell Science Publications; 1998. p. 1-8.

14. Hulsmann M, Peters O, Dummer M. Mechanical preparation of root canals: Shaping goals, techniques and means. Endodontic Topics. 2005;10:30-76.

15. Haapasalo M, Shen Y, Qian W, Gao Y. Irrigation in endodontics. Dent.Clin.North Am. 2010;54:291-312.

16. Bystrom A, Sundqvist G. The antibacterial action of sodium hypochlorite and EDTA in 60 cases of endodontic therapy. Int Endod J. 1985;18:35-40.

17. Bystrom A, Sundqvist G. Bacteriologic evaluation of the effect of 0.5 percent sodium hypochlorite in endodontic therapy. Oral Surg Oral Med Oral Pathol. 1983;55:307-12.

18. Byström A, Sundqvist G. Bacteriologic evaluation of the efficacy of mechanical root canal instrumentation in endodontic therapy. Scand J Dent Res. 1981;89:321-8.

19. Vianna ME, Horz HP, Gomes BPFA, Conrads G. In vivo evaluation of microbial reduction after chemo-mechanical preparation of human root canals containing necrotic pulp tissue. Int Endod J. 2006;39:484-92.

20. Sjögren U, Figdor D, Persson S, Sundqvist G. Influence of infection at the time of root filling on the outcome of endodontic treatment of teeth with apical periodontitis. Int Endod J. 1997;30:297-306.

21. Sedgley CM, Messer HH. Are endodontically treated teeth more brittle? J Endod. 1992;18:332-5.

22. Schilder H. Cleanign and shaping the root canal. Dent Clin North Am. 1974;18:269296.

23. Christie WH, Thompson GK. The importance of endodontic access in locating maxillary and mandibular molar canals. J Can Dent Assoc. 1994;60:527,532, 535.

24. Ingle JI. Endodontic cavity preparation. In: Ingle J, Tamber J, editors. Endodontics. Third ed. Philadelphia: Lea \& Febiger; 1985. p. 102-67.

25. Patel S, Rhodes J. A practical guide to endodontic access cavity preparation in molar teeth. Brit Dent J. 2007;203:133-40.

26. Clark D, Khademi J. Modern molar endodontic access and directed dentin conservation. Dent Clin North Am. 2010;54:249-73.

27. Clark D, Khademi JA. Case studies in modern molar endodontic access and directed dentin conservation. Dent Clin North Am. 2010;54:275-89. 
28. Ree M, Schwartz RS. The endo-restorative interface: Current concepts. Dent Clin North Am. 2010;54:345-74.

29. Fokkinga WA, Le Bell A-, Kreulen CM, Lassila LVJ, Vallittu PK, Creugers NHJ. Ex vivo fracture resistance of direct resin composite complete crowns with and without posts on maxillary premolars. Int Endod J. 2005;38:230-7.

30. Al-Omiri MK, Al-Wahadni AM. An ex vivo study of the effects of retained coronal dentine on the strength of teeth restored with composite core and different post and core systems. Int Endod J. 2006;39:890-9.

31. Reeh ES, Messer HH, Douglas WH. Reduction in tooth stiffness as a result of endodontic and restorative procedures. J Endod. 1989;15:512-6.

32. Young GR, Parashos P, Messer HH. The principles of techniques for cleaning root canals. Aust Dent J. 2007;52(1 SUPPL.):S52-63.

33. Hülsmann M, Gambal A, Bahr R. An improved technique for the evaluation of root canal preparation. J Endod. 1999;25:599-602.

34. Kazemi RB, Stenman E, Spångberg LSW. Machining efficiency and wear resistance of nickel-titanium endodontic files. Oral Surg Oral Med Oral Pathol Oral Radiol Endod. 1996;81:596-602.

35. Kuhn WG. Effect of tip design of nickel-titanium and stainless steel files on root canal preparation. J Endod. 1997;23:735-8.

36. Peters OA. Current challenges and concepts in the preparation of root canal systems: A review. J Endod. 2004;30:559-67.

37. Pettiette MT, Olutayo Delano E, Trope M. Evaluation of success rate of endodontic treatment performed by students with stainless-steel $\mathrm{k}$-files and nickel-titanium hand files. J Endod. 2001;27:124-7.

38. Webber J, Machtou P, Pertot W. The WaveOne single-file reciprocating system. Roots. 2011;1:28-33.

39. Metzger Z, Teperovich E, Zary R, Cohen R, Hof R. The self-adjusting file (SAF). part 1: Respecting the root canal anatomy-A new concept of endodontic files and its implementation. J Endod. 2010;36:679-90.

40. Franco V, Fabiani C, Taschieri S, Malentacca A, Bortolin M, Del Fabbro M. Investigation on the shaping ability of nickel-titanium files when used with a reciprocating motion. J Endod. 2011;37:1398-401. 
41. Yared G. Canal preparation using only one ni-ti rotary instrument: Preliminary observations. Int Endod J. 2008;41:339-44.

42. Plotino G, Grande NM, Testarelli L, Gambarini G. Cyclic fatigue of reciproc and WaveOne reciprocating instruments. Int Endod J. 2012;45:614-8.

43. Pirani C, Ruggeri O, Cirulli PP, Pelliccioni GA, Gandolfi MG, Prati C. Metallurgical analysis and fatigue resistance of WaveOne and ProTaper nickel-titanium instruments. Odontology. 2013:1-6.

44. De-Deus G, Moreira EJL, Lopes HP, Elias CN. Extended cyclic fatigue life of F2 ProTaper instruments used in reciprocating movement. Int Endod J. 2010;43:1063-8.

45. You S, Kim H, Bae K, Baek S, Kum K, Lee W. Shaping ability of reciprocating motion in curved root canals: A comparative study with micro-computed tomography. J Endod. 2011;37:1296-300.

46. Machado MEL, Nabeshima CK, Leonardo MFP, Reis FAS, Britto MLB, Cai S. Influence of reciprocating single-file and rotary instrumentation on bacterial reduction on infected root canals. Int Endod J. 2013.

47. Roane JB, Sabala CL, Duncanson Jr. MG. The "balanced force" concept for instrumentation of curved canals. J Endod. 1985;11:203-11.

48. Swain MV, Xue J. State of the art of micro-CT applications in dental research. Int J Oral Sci. 2009;1:177-88.

49. Lee J, Ha B, Choi J, Heo S, Perinpanayagam H. Quantitative three-dimensional analysis of root canal curvature in maxillary first molars using micro-computed tomography. J Endod. 2006;32:941-5.

50. Gao Y, Peters OA, Wu H, Zhou X. An application framework of three-dimensional reconstruction and measurement for endodontic research. J Endod. 2009;35:269-74.

51. Bergmans L, Van Cleynenbreugel J, Wevers M, Lambrechts P. A methodology for quantitative evaluation of root canal instrumentation using microcomputed tomography. Int Endod J. 2001;34:390-8.

52. Nielsen RB, Alyassin AM, Peters DD, Carnes DL, Lancaster J. Microcomputed tomography: An advanced system for detailed endodontic research. J Endod. 1995;21:561-8.

53. Peters OA, Laib A, Rüegsegger P, Barbakow F. Three-dimensional analysis of root canal geometry by high-resolution computed tomography. J Dent Res. 2000;79:1405-9. 
54. Peters OA, Laib A, Gohring TN, Barbakow F. Changes in root canal geometry after preparation assessed by high-resolution computed tomography. J Endod. 2001;27:1-6.

55. Peters OA, Schonenberger K, Laib A. Effects of four ni-ti preparation techniques on root canal geometry assessed by micro computed tomography. Int Endod J. 2001;34:22130 .

56. Peters OA, Peters CI, Schonenberger K, Barbakow F. ProTaper rotary root canal preparation: Effects of canal anatomy on final shape analysed by micro CT. Int Endod J. 2003;36:86-92.

57. Peters OA, Boessler C, Paqué F. Root canal preparation with a novel nickel-titanium instrument evaluated with micro-computed tomography: Canal surface preparation over time. J Endod. 2010;36:1068-72.

58. Paqué F, Ganahl D, Peters OA. Effects of root canal preparation on apical geometry assessed by micro-computed tomography. J Endod. 2009;35:1056-9.

59. Paqué F, Balmer M, Attin T, Peters OA. Preparation of oval-shaped root canals in mandibular molars using nickel-titanium rotary instruments: A micro-computed tomography study. J Endod. 2010;36:703-7.

60. Markvart M, Darvann TA, Larsen P, Dalstra M, Kreiborg S, Bjørndal L. Micro-CT analyses of apical enlargement and molar root canal complexity. Int Endod J. 2012;45:273-81.

61. Gantt DG, Kappleman J, Ketcham RA, Alder ME, Deahl TH. Three-dimensional reconstruction of enamel thickness and volume in humans and hominoids. Eur J Oral Sci. 2006;114(SUPPL. 1):360-4.

62. Maret D, Molinier F, Braga J, Peters OA, Telmon N, Treil J, et al. Accuracy of 3D reconstructions based on cone beam computed tomography. J Dent Res. 2010;89:1465-9.

63. Loushine RJ, Norman Weller R, Hartwell GR. Stereomicroscopic evaluation of canal shape following hand, sonic, and ultrasonic instrumentation. J Endod. 1989;15:417-21.

64. Stamos DE, Sadeghi EM, Haasch GC, Gerstein H. An in vitro comparison study to quantitate the debridement ability of hand, sonic, and ultrasonic instrumentation. $\mathrm{J}$ Endod. 1987; 13:434-40.

65. Rhodes JS, Pitt Ford TR, Lynch JA, Liepins PJ, Curtis RV. Micro-computed tomography: A new tool for experimental endodontology. Int Endod J. 1999;32:165-70.

66. Mondelli J, Steagall L, Ishikirriama A. Journal of Prosthetic Dentistry. 1980;43:419422. 
67. Pantvisai P, Messer HH. Cuspal deflection in molars in relation to endodontic and restorative procedures. J Endod. 1995;21:57-61.

68. Owen CP. Factors influencing the retention and resistance of preparations for cast intracoronal restorations. J Prosthet Dent. 1986;55:674-7.

69. Kishen A. Mechanisms and risk factors for fracture predilection in endodontically treated teeth. Endodontic Topics. 2006;13:57-83.

70. About instron [Internet]. USA; 2013; cited July 2013]. Available from: http://www.instron.com.

71. Assif D, Nissan J, Gafni Y, Gordon M. Assessment of the resistance to fracture of endodontically treated molars restored with amalgam. J Prosthet Dent. 2003;89:462-5.

72. Yamada Y, Tsubota Y, Fukushima S. Effect of restoration method on fracture resistance of endodontically treated maxillary premolars. Int J Prosthodontics. 2004;17:94-8.

73. Cobankara FK, Unlu N, Cetin AR, Ozkan HB. The effect of different restoration techniques on the fracture resistance of endodontically-treated molars. Oper Dent. 2008;33(5):526-33.

74. Soares CJ, Martins LRM, Pfeifer JMGA, Giannini M. Fracture resistance of teeth restored with indirect-composite and ceramic inlay systems. Quintessence Int.

2004;35:281-6.

75. Bader JD, Martin JA, Shugars DA. Incidence rates for complete cusp fracture. Community Dent Oral Epidemiol. 2001;29:346-53.

76. Fennis WMM, Kuijs RH, Kreulen CM, Roeters FJM, Creugers NHJ, Burgersdijk $\mathrm{RCW}$. A survey of cusp fractures in a population of general dental practices. Int J Prosthodontics. 2002;15:559-63.

77. Wahl MJ, Schmitt MM, Overton DA, Gordon MK. Prevalence of cusp fractures in teeth restored with amalgam and with resin-based composite. J Am Dent Assoc.

2004;135:1127-32.

78. Wu M, Van Der Sluis LWM, Wesselink PR. Comparison of mandibular premolars and canines with respect to their resistance to vertical root fracture. J Dent. 2004;32:2658 .

79. Tang $\mathrm{W}, \mathrm{Wu} \mathrm{Y}$, Smales RJ. Identifying and reducing risks for potential fractures in endodontically treated teeth. J Endod. 2010;36:609-17. 
80. Ng YL, Mann V, Rahbaran S, Lewsey J, Gulabivala K. Outcome of primary root canal treatment: Systematic review of the literature - part 1. effects of study characteristics on probability of success. Int Endod J. 2007;40:921-39.

81. de Chevigny C, Dao TT, Basrani BR, Marquis V, Farzaneh M, Abitbol S, et al. Treatment outcome in endodontics: The toronto study-phase 4: Initial treatment. J Endod. 2008;34:258-63.

82. Reit C, Hollender L. Radiographic evaluation of endodontic therapy and the influence of observer variation. Scand J Dent Res. 1983;91:205-12.

83. Lambrianidis T. Observer variations in radiographic evaluation of endodontic therapy. Endod Dent Traumatol. 1985;1:235-41.

84. Goldman M, Pearson AH, Darzenta N. Reliability of radiographic interpretations. Oral Surg Oral Med Oral Pathol. 1974;38:287-93.

85. Zakariasen KL, Scott DA, Jensen JR. Endodontic recall radiographs: How reliable is our interpretation of endodontic success or failure and what factors affect our reliability? Oral Surg Oral Med Oral Pathol. 1984;57:343-7.

86. Friedman S. Endodontic treatment outcome: The potential for healing and retained function. In: Ingle J, Bakland LK, Baumgartner C, editors. Endodontics. 6th ed. Philadelphia: BC Decker; 2008.

87. Ng YL, Mann V, Gulabivala K. A prospective study of the factors affecting outcomes of nonsurgical root canal treatment: Part 1: Periapical health. Int Endod J. 2011;44(7):583-609.

88. Ng YL, Mann V, Gulabivala K. Tooth survival following non-surgical root canal treatment: A systematic review of the literature. Int Endod J. 2010;43:171-89.

89. Tan PL, Aquilino SA, Gratton DG, Stanford CM, Tan SC, Johnson WT, et al. In vitro fracture resistance of endodontically treated central incisors with varying ferrule heights and configurations. J Prosthet Dent. 2005;93:331-6.

90. Gulabivala K. Restoration of the root-treated tooth. In: Stock C, Walker R, Gulabivala K, editors. Third ed. Oxford, Great Britain: Elsevier Mosby; 2004. p. 279306.

91. Assif D, Gorfil C. Biomechanical considerations in restoring endodontically treated teeth. J Prosthet Dent. 1994;71:565-7.

92. Johnson JK, Schwartz NL, Blackwell RT. Evaluation and restoration of endodontically treated posterior teeth. J Am Dent Assoc. 1976;93:597-605. 
93. Linn J, Messer HH. Effect of restorative procedures on the strength of endodontically treated molars. J Endod. 1994;20:479-85.

94. Caplan DJ, Cai J, Yin G, White BA. Root canal filled versus non-root canal filled teeth: A retrospective comparison of survival times. J Publ Health Dent. 2005;65:90-6.

95. Chen S, Chueh L, Hsiao CK, Wu H, Chiang C. First untoward events and reasons for tooth extraction after nonsurgical endodontic treatment in taiwan. J Endod. 2008;34:6714.

96. Touré B, Faye B, Kane AW, Lo CM, Niang B, Boucher Y. Analysis of reasons for extraction of endodontically treated teeth: A prospective study. J Endod. 2011;37:1512-5.

97. Tzimpoulas NE, Alisafis MG, Tzanetakis GN, Kontakiotis EG. A prospective study of the extraction and retention incidence of endodontically treated teeth with uncertain prognosis after endodontic referral. J Endod. 2012;38:1326-9.

98. Vire DE. Failure of endodontically treated teeth: Classification and evaluation. J Endod. 1991 Jul;17:338-42.

99. Hansen EK. In vivo cusp fracture of endodontically treated premolars restored with MOD amalgam or MOD resin fillings. Dent Mater. 1988;4:169-73.

100. Hansen EK, Asmussen E. In vivo fractures of endodontically treated posterior teeth restored with enamel-bonded resin. Endod Dent Traumatol. 1990;6:218-25.

101. Hansen EK, Asmussen E, Christiansen NC. In vivo fractures of endodontically treated posterior teeth restored with amalgam. Endod Dent Traumatol. 1990;6:49-55.

102. Bader JD, Shugars DA, Sturdevant JR. Consequences of posterior cusp fracture. Gen Dent. 2004;52:128-31.

103. Peters OA, Boessler C, Paque F. Root canal preparation with a novel nickel-titanium instrument evaluated with micro-computed tomography: Canal surface preparation over time. J Endod. 2010;36:1068-72.

104. Paqué F, Balmer M, Attin T, Peters OA. Preparation of oval-shaped root canals in mandibular molars using nickel-titanium rotary instruments: A micro-computed tomography study. J Endod. 2010;36:703-7.

105. Bürklein S, Schäfer E. The influence of various automated devices on the shaping ability of mtwo rotary nickel-titanium instruments. Int Endod J. 2006;39:945-51.

106. Bürklein S, Hiller C, Huda M, Schäfer E. Shaping ability and cleaning effectiveness of mtwo versus coated and uncoated EasyShape instruments in severely curved root canals of extracted teeth. Int Endod J. 2011;44:447-57. 
107. Bürklein S, Hinschitza K, Dammaschke T, Schäfer E. Shaping ability and cleaning effectiveness of two single-file systems in severely curved root canals of extracted teeth: Reciproc and WaveOne versus mtwo and ProTaper. Int Endod J. 2012;45:449-61.

108. Schäfer E, Vlassis M. Comparative investigation of two rotary nickel-titanium instruments: ProTaper versus RaCe. part 2. cleaning effectiveness and shaping ability in severely curved root canals of extracted teeth. Int Endod J. 2004;37:239-48.

109. Zhi-Yue L, Yu-Xing Z. Effects of post-core design and ferrule on fracture resistance of endodontically treated maxillary central incisors. J Prosthet Dent. 2003;89:368-73.

110. Wendt Jr. SL, Harris BM, Hunt TE. Resistance to cusp fracture in endodontically treated teeth. Dent Mater. 1987;3(5):232-5.

111. Boveda C. Personal communication.

http://www.carlosboveda.com/casosclinicos.htm

112. de Moura-Netto C, Palo RM, Camargo CHR, Pameijer CH, da Silva Bardauil MRR. Micro-CT assessment of two different endodontic preparation systems. Braz Oral Res. 2013;27:26-30.

113. Wu MK, R'oris A, Barkis D, Wesselink PR. Prevalence and extent of long oval canals in the apical third. Oral Surg Oral Med Oral Pathol Oral Radiol Endod. 2000;89:739-43.

114. Weiger R, ElAyouti A, Löst C. Efficiency of hand and rotary instruments in shaping oval root canals. J Endod. 2002;28:580-3.

115. Paqué F, Peters OA. Micro-computed tomography evaluation of the preparation of long oval root canals in mandibular molars with the self-adjusting file. J Endod. 2011;37:517-21.

116. Akerboom HB, Advokaat JG, Van Amerongen WE, Borgmeijer PJ. Long-term evaluation and rerestoration of amalgam restorations. Community Dent Oral Epidemiol. 1993;21:45-8.

117. Ng YL, Mann V, Gulabivala K. A prospective study of the factors affecting outcomes of non-surgical root canal treatment: Part 2: Tooth survival. Int Endod J. 2011;44:610-25.

118. Nagasiri R, Chitmongkolsuk S. Long-term survival of endodontically treated molars without crown coverage: A retrospective cohort study. J Prosthet Dent. 2005;93:164-70.

119. Voros S, Long J, Cinquin P. Automatic detection of instruments in laparoscopic images: A first step towards high-level command of robotic endoscopic holders. Int J Rob Res. 2007;26:1173-90. 
120. Magne P. Efficient 3D finite element analysis of dental restorative procedures using micro-CT data. Dent Mater. 2007;23:539-48.

121. Srirekha A, Bashetty K. Infinite to finite: An overview of finite element analysis.

Indian J Dent Res. 2010;21:425-32.

122. Kishen A, Kumar GV, Chen NN. Stress-strain response in human dentine:

Rethinking fracture predilection in postcore restored teeth. Dent Traumatol. 2004;20:90100 . 


\section{APPENDICES}

\section{Appendix 1. Figures}

Figure 1: Separate and merged pre-treatment (green) and post-treatment (red) micro-CT images of mandibular premolar (mesial view) where the root canal was accessed and instrumented through TEC with the green surface in the merged image representing untouched canal wall area.
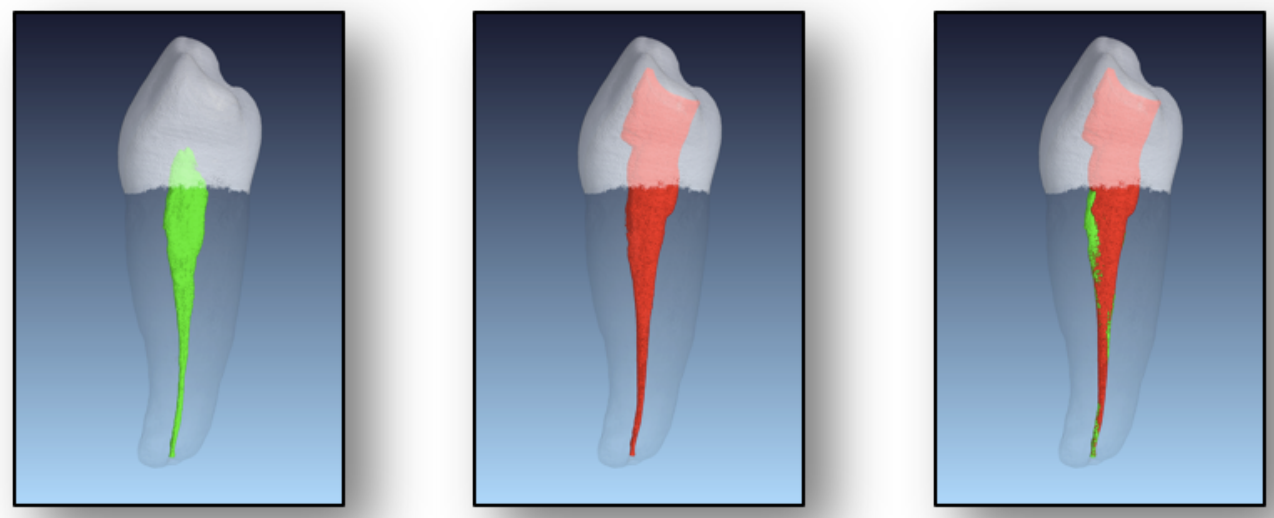

Figure 2: Separate and merged pre-treatment (green) and post-treatment (red) micro-CT images of a mandibular premolar (mesial view) where the root canal was accessed and instrumented through CEC with the green surface in the merged image representing untouched canal wall area.
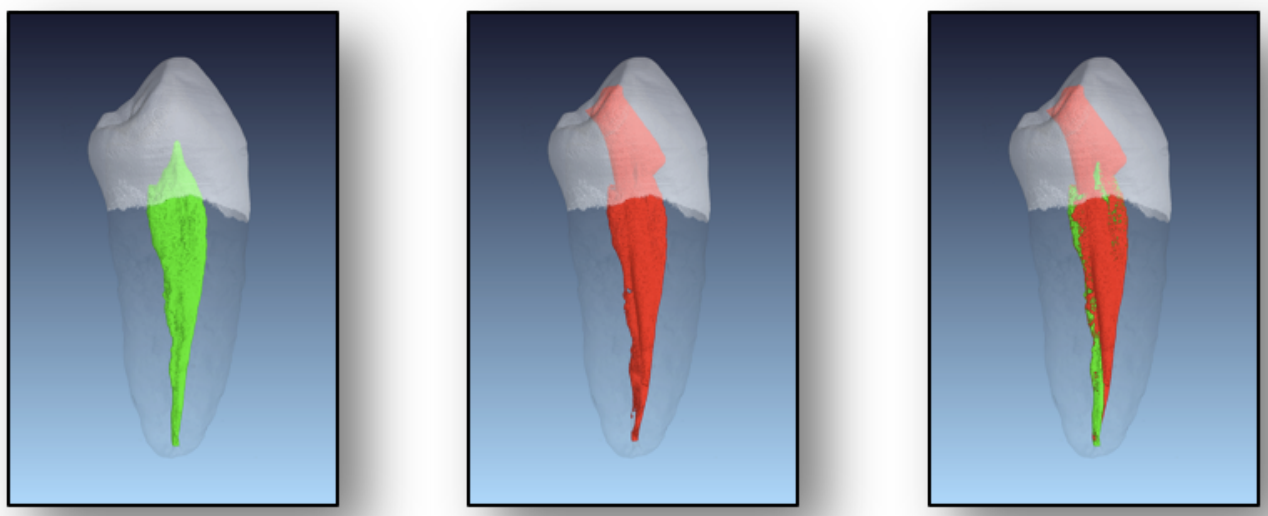
Figure 3: Load-at-fracture (mean and standard deviation) for extracted teeth with conservative (CEC), traditional (TEC) or no endodontic cavities (negative control), assessed in the Instron Universal Testing machine. Similar letter case designation indicates non-significant differences; different letter case designations indicate a significant difference $(\mathrm{p}<0.05)$.

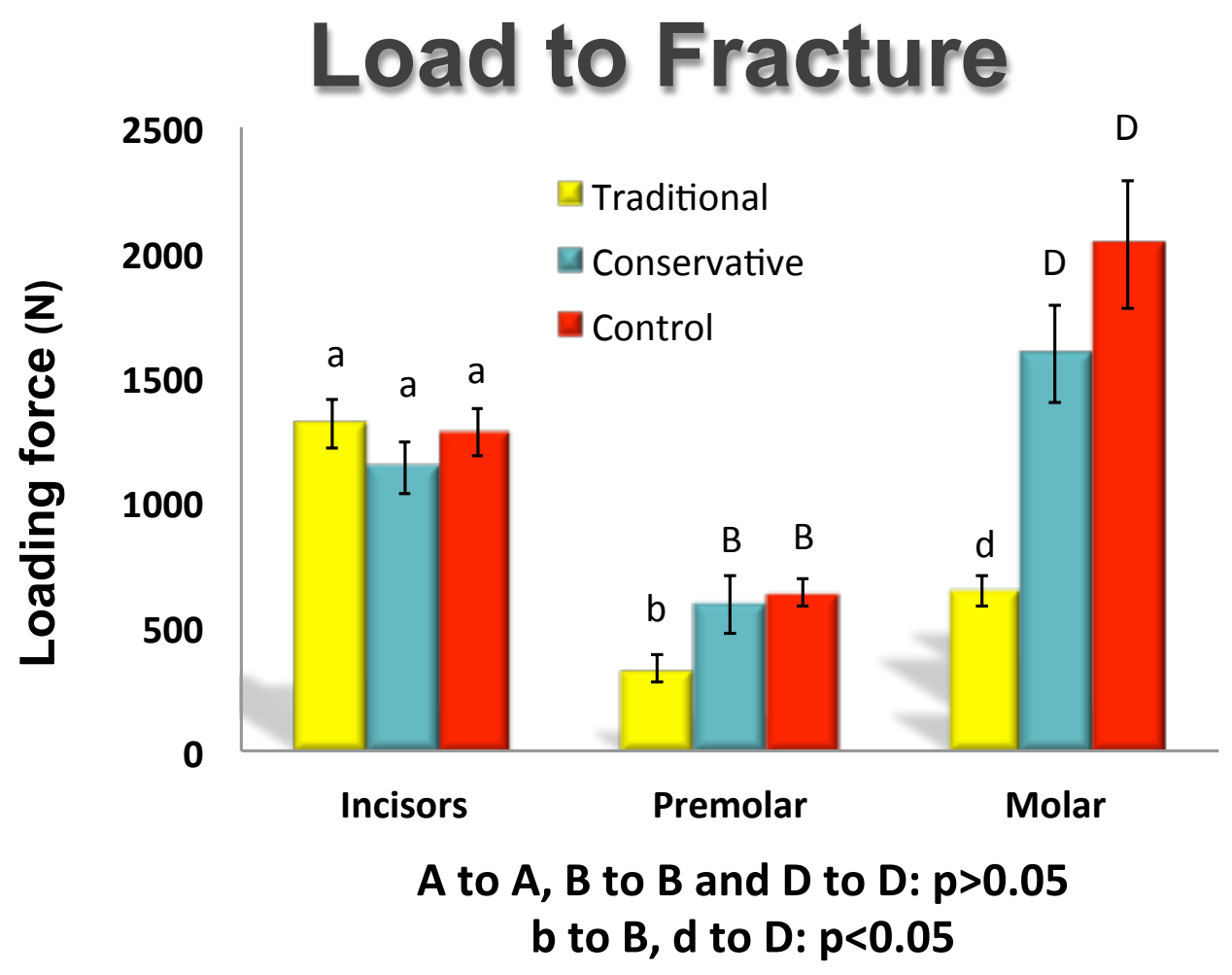


Figure 4: Typical fracture patterns in maxillary central incisors with CEC and TEC, loaded to fracture in the Instron Universal machine. Note the variable fracture patterns in teeth with both CEC and TEC.
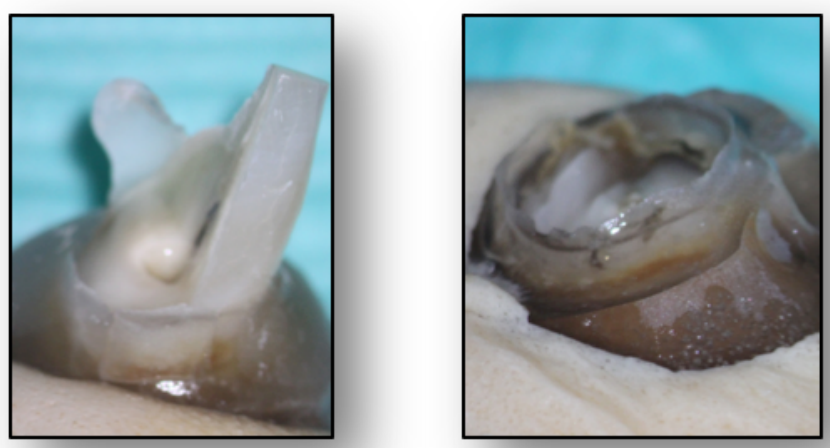

Figure 5: Typical fracture patterns in mandibular molars with CEC and TEC, loaded to fracture in the Instron Universal Testing machine. Note the mesio-distal fractures with varying apical extent observed in both CEC (left) and TEC (right).
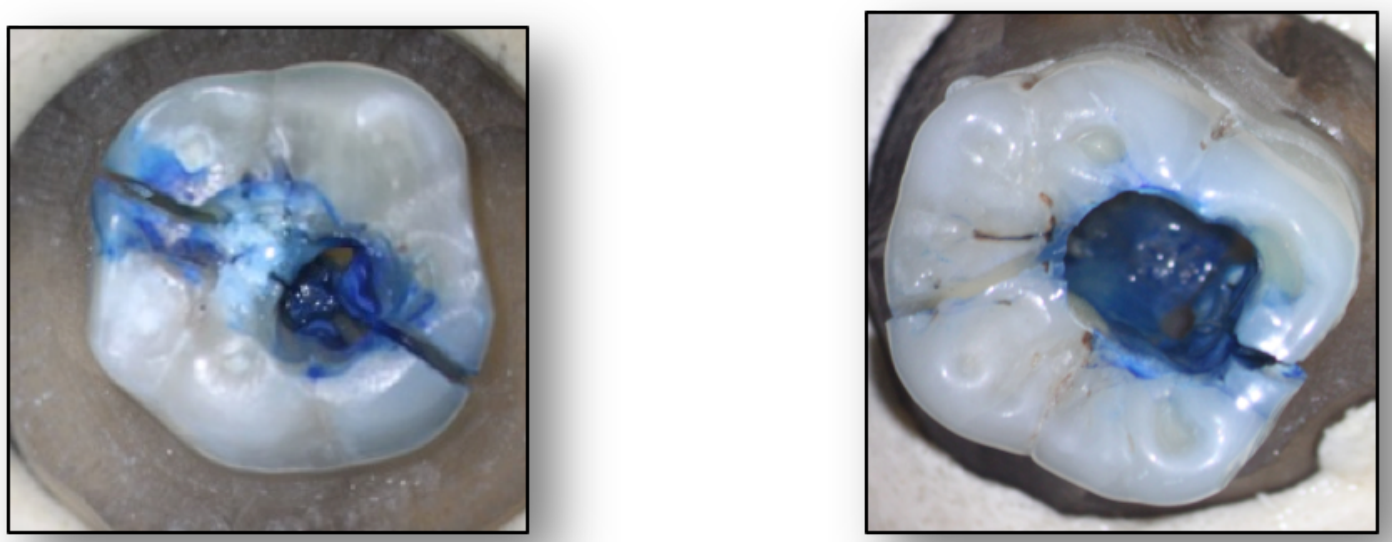
Figure 6: A typical outline of a conservative endodontic cavity (CEC) on the left and the outline of a traditional endodontic cavity (TEC) on the right, in mandibular molars.
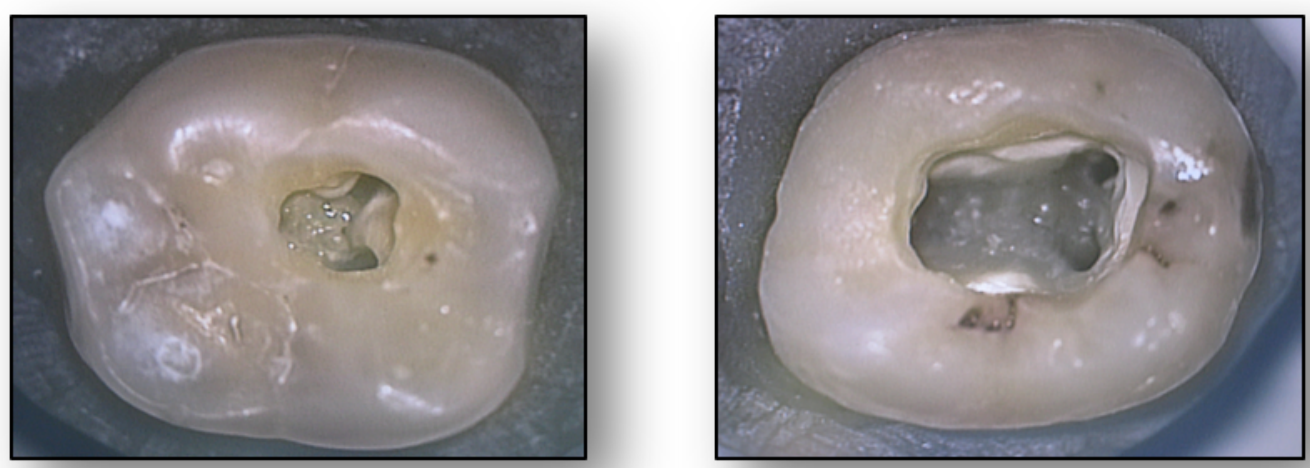